\title{
Evidence for Iron Nanoparticles Catalyzing the Rapid Dehydrogenation of Ammonia- Borane
}

\author{
Jessica F. Sonnenberg and Robert H. Morris \\ Version Post-print/accepted manuscript \\ Citation Sonnenberg, J. F., \& Morris, R. H. (2013). Evidence for iron \\ (published version) nanoparticles catalyzing the rapid dehydrogenation of ammonia-borane. \\ ACS Catalysis, 3 (6), 1092-1102 DOI: 10.1021/cs400115p \\ Publisher's statement This document is the Accepted Manuscript version of a Published \\ Work that appeared in final form in ACS Catalysis, copyright (C) \\ American Chemical Society after peer review and technical editing by \\ the publisher. To access the final edited and published work see \\ http://dx.doi.org/10.1021/cs400115p
}

How to cite TSpace items

\begin{abstract}
Always cite the published version, so the author(s) will receive recognition through services that track citation counts, e.g. Scopus. If you need to cite the page number of the author manuscript from TSpace because you cannot access the published version, then cite the TSpace version in addition to the published version using the permanent URI (handle) found on the record page.
\end{abstract}

This article was made openly accessible by $U$ of $T$ Faculty. Please tell us how this access benefits you. Your story matters. 


\title{
Evidence for Iron Nanoparticles Catalysing the Rapid Dehydrogenation of Ammonia- Borane
}

\author{
Jessica F. Sonnenberg and Robert H. Morris*
}

Davenport Laboratories, Department of Chemistry, University of Toronto, 80 St. George Street, Toronto, Ontario, M5S $3 \mathrm{H} 6$

Robert.Morris@utoronto.ca; jessica.sonnenberg@mail.utoronto.ca

\begin{abstract}
A series of precatalysts of the general formula $\left[\mathrm{Fe}(\mathrm{NCMe})(\mathrm{L})\left(\mathrm{PPh}_{2} \mathrm{C}_{6} \mathrm{H}_{4} \mathrm{CH}=\mathrm{NCHR}-\right)_{2}\right]\left[\mathrm{BF}_{4}\right]_{2}$ (where $\mathrm{L}=\mathrm{CO}$ or $\mathrm{NCMe}$, and $\mathrm{R}=\mathrm{Ph}$ or $\mathrm{H}$ ) were tested for the dehydrogenation of amine-boranes. They have already been used in our lab for the transfer hydrogenation or direct hydrogenation of ketones and the oxidative kinetic resolution of alcohols. We compared a series of sterically- $(\mathrm{R}=\mathrm{H}$ or $\mathrm{Ph})$ and electronically- $(\mathrm{L}=\mathrm{NCMe}$ or $\mathrm{CO})$ varied precatalysts in both protic and aprotic solvents for the release of hydrogen from ammonia-borane $(\mathrm{AB})$ and studied the products by NMR. At room temperature in THF we optimized our systems, and achieved maximum turn-over frequencies (TOF) of up to $3.66 \mathrm{H}_{2} / \mathrm{sec}$ and 1.8 total $\mathrm{H}_{2}$ equivalents, and in isopropanol we were able to release a maximum of 2.9 equivalents $\mathrm{H}_{2}$ and reuse some of our catalytic systems. In previous mechanistic studies we provided strong evidence that the active species during $\mathrm{TH}$ and oxidation catalysis are zero-valent iron nanoparticles formed by the reduction of the Fe-PNNP precatalysts with base. To probe the dehydrogenation active species we successfully show comparable activity between preformed catalysts, and those generated in situ using commercially available $\mathrm{Fe}^{2+}$ sources and sub-stoichiometric amounts of PNNP ligand. This result, when paired with transmission electron microscope images of $\sim 4 \mathrm{~nm}$ iron nanoparticles of reaction solutions provide evidence that the highly active systems studied are heterogeneous in nature. This would be the first report of iron nanoparticles catalysing $\mathrm{H}_{2}$ evolution from $A B$ in non-protic solvents. We also report the evolution of hydrogen from dimethylamine-borane and the resultant product mixtures using the same catalyst series.
\end{abstract}

\section{Keywords}

Iron Nanoparticles, Ammonia-Borane Dehydrogenation, B-N Polymers, Heterogeneous, Hydrogen Evolution, Catalytic Profile, Electron Microscopy 


\section{Introduction}

The transition from high carbon content liquid and solid based fuels into gas based fuels for energy applications is of growing economic importance. ${ }^{1}$ Emerging as the ideal candidate as a clean, lightweight and high energy density fuel is hydrogen gas. ${ }^{2}$ Among the major challenges in the use of hydrogen is its storage and production in an efficient and 'green' way. ${ }^{3} \mathrm{~A}$ potential candidate to solve this problem is ammonia borane, $\mathrm{NH}_{3} \cdot \mathrm{BH}_{3}(\mathrm{AB})$, which has a total hydrogen content of $19.6 \mathrm{wt} \%$, or 6.5 and $13.1 \mathrm{wt} \%$ for the first and second equivalent of hydrogen released. ${ }^{4,5}$ When analysing catalysts for such a transformation it is important to study not only the number of equivalents of $\mathrm{H}_{2}$ released, but also the reaction conditions and type of $\mathrm{B} / \mathrm{N}$ containing products formed. ${ }^{4,6,7}$ There are a significant number of catalytic systems in the literature employing water and protic solvents for the dehydrogenation/hydrolysis of $A B,{ }^{4}$ and although larger numbers of equivalents of $\mathrm{H}_{2}$ are evolved, the formation of strong B-O bonds precludes their use in industry as the wastes are not recyclable. ${ }^{8}$ It is therefore important to generate catalysts that operate in non-protic solvents such as THF, aromatic solvents or glyme, as the typical products contain $\mathrm{B}-\mathrm{N}$ bonds which can be used to regenerate AB. ${ }^{8}$

There are several homogeneous systems in the literature based on precious metal catalysts, ${ }^{9-18}$ as well as more abundant metals such as titanium, ${ }^{19}$ nickel ${ }^{20,21}$ and iron, ${ }^{7,22}$ and group 6 metal carbonyls ${ }^{23}$ that have been used as dehydrogenation catalysts. Heterogeneous catalysts have also been studied, primarily using precious metal catalysts, ${ }^{24-28}$ although there are reports using nickel heterogeneous catalysts $^{29}$ for the dehydrogenation of amine-boranes, including ammonia-borane. In the field of iron catalysts for this transformation a few key discoveries stand out as stepping stones. First was the work by Xu et. $a .^{30}$ who reduced $\mathrm{Fe}\left(\mathrm{SO}_{4}\right)$ to generate stable, $3 \mathrm{~nm}$, zero-valent iron nanoparticles (FeNPs) that were able to evolve three equivalents of hydrogen from ammonia-borane in water at room temperature. Their catalyst was stable under air and magnetically recyclable, however it was only used for hydrolysis of $A B$ to generate borates, not B-N polymers or oligomers. The next key example was the use of $\left[\left\{\mathrm{CpFe}(\mathrm{CO})_{2}\right\}_{2}\right]$ under photoirradiation to dehydrogenate amine-boranes by Manners et. al. ${ }^{22}$ wherein they also determined the identity of several of the products and intermediates during the reaction. Baker et. al. ${ }^{7}$ used iron systems with phosphine and amido ligands to evolve 1-2 equivalents of $\mathrm{H}_{2}$ and generate $\left(\mathrm{BH}_{2} \mathrm{NH}_{2}\right)_{n}$ and $(\mathrm{BHNH})_{n}$ oligomers. Their active systems are hypothesized to be based on zero-valent iron systems stabilized by ligands. There is therefore a vacancy in the literature in terms of using defined heterogeneous iron catalyst for the dehydrogenation of amine-boranes to yield B-N polymers and oligomers.

Figure 1: Precatalyst structures for systems investigated for ammonia-borane dehydrogenation reactions including ligands tested

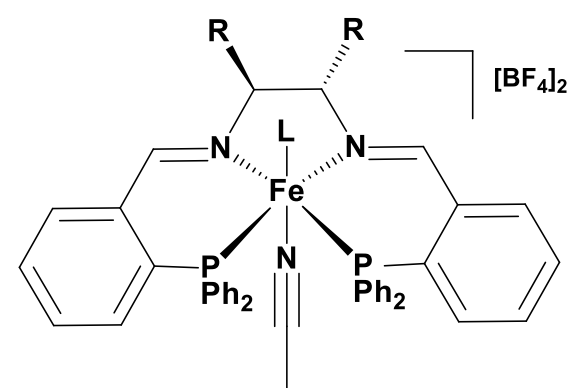

$\mathrm{L}=\mathrm{NCMe}, \mathrm{R}=\mathrm{H}(\mathbf{1})$

$\mathrm{L}=\mathrm{CO}, \mathrm{R}=\mathrm{H}(\mathbf{2})$

$\mathrm{L}=\mathrm{NCMe}, \mathrm{R}=\mathrm{Ph}(\mathbf{3})$

$\mathrm{L}=\mathrm{CO}, \mathrm{R}=\mathrm{Ph}(\mathbf{4})$

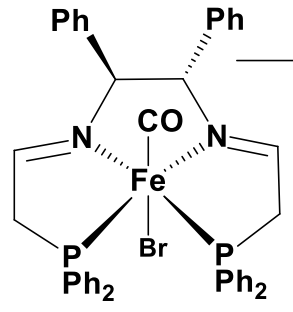

$(\mathbf{S}, \mathbf{S},-\mathbf{7})$

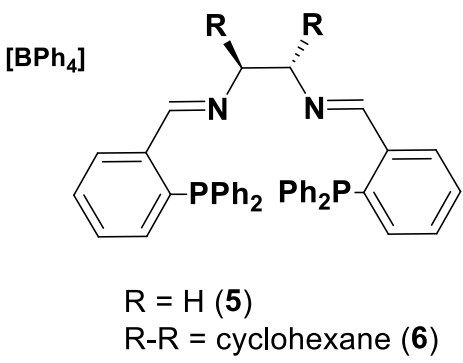


Our group has reported the synthesis of iron complexes of the general formula $[\mathrm{Fe}(\mathrm{NCMe})(\mathrm{L})(\mathrm{PNNP})]\left[\mathrm{BF}_{4}\right]_{2}$ where $\mathrm{L}=\mathrm{NCMe}$ or $\mathrm{CO}$ and $\mathrm{PNNP}=\left(\mathrm{PPh}_{2} \mathrm{C}_{6} \mathrm{H}_{4} \mathrm{CH}=\mathrm{NCHR}-\right)_{2}$, as depicted in Figure 1 , which have been shown to be highly active for direct $\mathrm{H}_{2}$-hydrogenation of ketones ${ }^{31}(\mathrm{~L}=\mathrm{NCMe})$ and for the transfer hydrogenation ( $\mathrm{TH}$ ) of ketones using isopropanol (iPrOH) as the hydrogen source ${ }^{32}$ $(\mathrm{L}=\mathrm{CO})$. Upon further investigation of the catalyst during $\mathrm{TH}$ we proposed that the active catalytic species are zero-valent iron nanoparticles (FeNPs). This proposition was based on DFT support for a low energy pathway for the formation of iron $(0)^{33}$ as well as extensive poisoning, imaging and in operando experiments. ${ }^{34}$ The FeNPs are proposed to be a zero-valent iron core, coated in PNNP ligand, able to bind substrate to active sites and transfer a proton and hydride equivalent. These nanoparticle catalysts were further probed and shown to be active for the reverse process; oxidative kinetic resolution of aromatic alcohols to enantio-enriched alcohols and ketones, and their heterogeneity was similarly probed. ${ }^{35}$ These precatalysts with the general formula $\left[\mathrm{Fe}(\mathrm{NCMe})(\mathrm{L})(\mathrm{PNNP}]\left[\mathrm{BF}_{4}\right]_{2}\right.$ have therefore proven themselves to be quite versatile in terms of their chemistry with hydrogen, and we were therefore interested in probing their ability to act as hydrogen evolving catalysts in the dehydrogenation of ammonia-borane, as depicted in Scheme 1 for our optimized reaction conditions. The use of alcohol oxidation/reduction catalysts for amine-borane dehydrogenation has been previously reported using $\mathrm{Ru}(\mathrm{PN})_{2}$ catalysts ${ }^{11}$ and were found to be quite active in terms of both rates and extent of $\mathrm{H}_{2}$ release.

Scheme 1: Generalized reaction scheme and product distribution for optimized catalytic system

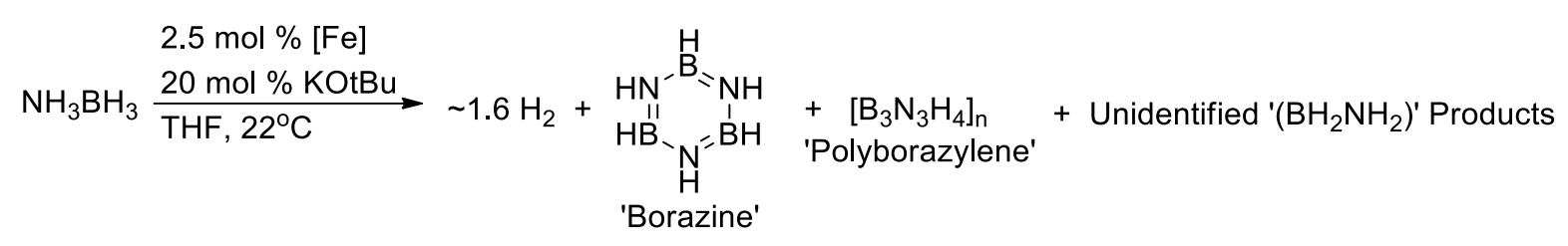

\section{Experimental}

\section{General Procedures}

All preparations, manipulations and catalysis were carried out under argon or nitrogen atmosphere using standard Schlenk line and drybox techniques. Dry and oxygen-free solvents were distilled and dried using the appropriate drying agents. NMR solvents were purchased from Aldrich and degassed and dried over activated molecular sieves. All other reagents were purchased from various commercial sources and used without further purification. NMR spectra were recorded using a Bruker 400 and a Varian 400 spectrometer to determine ${ }^{1} \mathrm{H}(400 \mathrm{MHz}),{ }^{11} \mathrm{~B}(128 \mathrm{MHz})$ and ${ }^{31} \mathrm{P}\left\{{ }^{1} \mathrm{H}\right\}(161 \mathrm{MHz})$ shifts.

Electron microscopy imaging was carried out at the Department of Pathology \& Laboratory Medicine in the Joseph \& Wolf Lebovic Health Complex at Mount Sinai Hospital in collaboration with Dr. Doug Holmyard on a Tecnai-20 using a GIF2000 energy filter. Samples were placed on an ultrathin carbon film supported by a lacey carbon film on a 400 mesh copper grid.

\section{Syntheses}

Precatalysts $\left[\mathrm{Fe}(\mathrm{NCMe})_{2}\left(\mathrm{P}_{2} \mathrm{~N}_{2} \mathrm{en}\right)\right]\left[\mathrm{BF}_{4}\right]_{2}(\mathbf{1})$, $\left[\mathrm{Fe}(\mathrm{CO})(\mathrm{NCMe})\left(\mathrm{P}_{2} \mathrm{~N}_{2} \mathrm{en}\right)\right]\left[\mathrm{BF}_{4}\right]_{2}(\mathbf{2})$, $\left[\mathrm{Fe}(\mathrm{NCMe})_{2}\left(\mathrm{P}_{2} \mathrm{~N}_{2} \mathrm{dpen}\right)\right][\mathrm{BF}]_{2}(\mathbf{R}, \mathbf{R}-\mathbf{3})$ and $\left[\mathrm{Fe}(\mathrm{CO})(\mathrm{NCMe})\left(\mathrm{P}_{2} \mathrm{~N}_{2} \mathrm{dpen}\right)\right][\mathrm{BF}]_{2}(\mathbf{R}, \mathbf{R}-\mathbf{4})$ and ligands $\left\{\left(\mathrm{PPh}_{2}\right.\right.$ (o$\left.\left.\left.\mathrm{C}_{6} \mathrm{H}_{4}\right) \mathrm{CH}=\mathrm{NHCH}_{2}-\right)_{2}\right\}:\left(\mathrm{P}_{2} \mathrm{~N}_{2} \mathrm{en}\right)(\mathbf{5})$ and $(\mathrm{R}, \mathrm{R})-\left\{\left(\mathrm{PPh}_{2}\left(\mathrm{O}-\mathrm{C}_{6} \mathrm{H}_{4}\right) \mathrm{CH}=\mathrm{NH}\left(\mathrm{C}_{6} \mathrm{H}_{10}\right) \mathrm{NH}=\mathrm{CH}\left(\mathrm{O}-\mathrm{C}_{6} \mathrm{H}_{4}\right) \mathrm{PPh}_{2}\right)\right\}:\left(\mathrm{P}_{2} \mathrm{~N}_{2} \mathrm{Cy}\right)$ 
(R,R-6) have been prepared and characterised previously. ${ }^{31,32,36,37}$ Precatalyst $(\mathrm{S}, \mathrm{S})$ -

$\left[\mathrm{Fe}(\mathrm{CO})(\mathrm{Br})\left(\mathrm{PPh}_{2} \mathrm{CH}_{2} \mathrm{CH}=\mathrm{NHCHPh}-\right)_{2}\right]\left[\mathrm{BPh}_{4}\right](\mathbf{S}, \mathrm{S}-\mathbf{7})$ has been prepared and characterized previously. ${ }^{38}$

\section{Catalysis}

In an argon filled glovebox, pre-catalyst and ammonia-borane (AB) were added to a $25 \mathrm{~mL}$ two-neck round-bottom flask which was sealed with a rubber septum and a $10 \mathrm{~mL}$ dry-addition flask containing KOtBu. The sealed system was removed from the glovebox and submerged in a bath at a set, regulated temperature before solvent was added to the flask and stirred for 10 minutes. A cannula needle was used to pierce the septum and monitor the evolution of gas into an upturned $50 \mathrm{~mL}$ burette filled with water. To start the reaction, the dry-addition flask was tilted, and base was added to the reaction, which was stirred vigorously. Hydrogen production was measured in terms of volume displacement of water in the burette as a measure of time. All catalytic results were reproduced in triplicate to ensure consistency.

Table 1. Reaction conditions for all catalytic hydrogen evolution reactions using iron catalysts

\begin{tabular}{|c|c|c|c|c|c|c|c|c|}
\hline $\begin{array}{c}\text { Ent } \\
\text { ry }\end{array}$ & $\begin{array}{c}\text { Catalyst } \\
\text { (mg, mmol) }\end{array}$ & $\begin{array}{c}\text { Other } \\
\text { (mg, mmol) }\end{array}$ & $\begin{array}{c}\mathrm{H}_{2} \text { Source } \\
\text { (mg, mmol) }\end{array}$ & $\begin{array}{c}\text { KOtBu } \\
\text { (mg, mmol) }\end{array}$ & $\mathrm{C}: \mathrm{B}: \mathrm{S}^{\mathrm{b}}$ & $\begin{array}{c}\text { Solvent } \\
\text { (mL, mmol) }\end{array}$ & $\begin{array}{c}\mathrm{T} \\
\left({ }^{\circ} \mathrm{C}\right)\end{array}$ & $\begin{array}{l}\text { Equiv. } \mathrm{H}_{2} \\
1 \mathrm{~min} / 1 \mathrm{~h}\end{array}$ \\
\hline 1 & (1) $(7,0.0076)$ & $\mathrm{N} / \mathrm{A}$ & $A B(10,0.32)$ & $(8,0.071)^{a}$ & 1:9:42 & $\mathrm{iPrOH}(5,65)$ & 22 & $0.93 / 2.50$ \\
\hline 2 & (2) $(7,0.0077)$ & $\mathrm{N} / \mathrm{A}$ & $A B(10,0.32)$ & $(8,0.071)^{a}$ & 1:9:42 & iPrOH $(5,65)$ & 22 & $0.15 / 2.58$ \\
\hline 3 & $\begin{array}{l}\mathbf{R}, \mathbf{R}-\mathbf{3})(9, \\
0.0084) \\
\end{array}$ & $\mathrm{N} / \mathrm{A}$ & $A B(10,0.32)$ & $(8,0.071)^{a}$ & $1: 8: 38$ & $\mathrm{iPrOH}(5,65)$ & 22 & $0.59 / 2.89$ \\
\hline 4 & $\begin{array}{l}(\mathbf{R}, \mathbf{R}-4)(9, \\
0.0085)\end{array}$ & $\mathrm{N} / \mathrm{A}$ & $A B(10,0.32)$ & $(8,0.071)^{a}$ & $1: 8: 38$ & iPrOH $(5,65)$ & 22 & $0.20 / 2.90$ \\
\hline 5 & $\begin{array}{l}{\left[\mathrm{Fe}\left(\mathrm{H}_{2} \mathrm{O}\right)_{6}\right]\left[\mathrm{BF}_{4}\right]_{2}} \\
(5,0.015)\end{array}$ & $\begin{array}{l}\text { (5) } \\
(5,0.0083)\end{array}$ & $A B(10,0.32)$ & $(10,0.089)^{a}$ & $1: 6: 21$ & iPrOH $(5,65)$ & 22 & $0.17 / 1.02$ \\
\hline 6 & (1) $(7,0.0076)$ & $\mathrm{N} / \mathrm{A}$ & $A B(10,0.32)$ & $(8,0.071)^{a}$ & $1: 9: 42$ & $\operatorname{THF}(5,62)$ & 22 & $1.13 / 1.60$ \\
\hline 7 & (1) $(7,0.0076)$ & $N / A$ & $A B(10,0.32)$ & $(8,0.071)^{a}$ & 1:9:42 & $\operatorname{THF}(5,62)$ & 2 & $0.95 / 1.40$ \\
\hline 8 & $(1)(7,0.0076)$ & $\begin{array}{l}\text { CO } \\
\text { headspace }\end{array}$ & $A B(10,0.32)$ & $(8,0.071)^{a}$ & 1:9:42 & $\operatorname{THF}(5,62)$ & 22 & $0.05 / 0.09$ \\
\hline 9 & (1) $(5,0.0055)$ & $\mathrm{N} / \mathrm{A}$ & $A B(20,0.64)$ & $(6,0.053)^{a}$ & 1:9:42 & $\operatorname{THF}(5,62)$ & 22 & $1.0 / 1.22$ \\
\hline 10 & (2) $(7,0.0077)$ & $N / A$ & $A B(10,0.32)$ & $(8,0.071)^{a}$ & 1:9:42 & $\operatorname{THF}(5,62)$ & 22 & $0.48 / 1.26$ \\
\hline 11 & $\begin{array}{l}\mathbf{R}, \mathbf{R}-\mathbf{3})(9, \\
0.0084)\end{array}$ & $\mathrm{N} / \mathrm{A}$ & $A B(10,0.32)$ & $(8,0.071)^{a}$ & $1: 8: 38$ & $\operatorname{THF}(5,62)$ & 22 & $1.14 / 1.71$ \\
\hline 12 & $\begin{array}{l}\text { (R,R-4) (9, } \\
0.0085)\end{array}$ & $\mathrm{N} / \mathrm{A}$ & $A B(10,0.32)$ & $(8,0.071)^{a}$ & $1: 8: 38$ & $\operatorname{THF}(5,62)$ & 22 & $0.80 / 1.44$ \\
\hline 13 & $\begin{array}{l}{\left[\mathrm{Fe}\left(\mathrm{H}_{2} \mathrm{O}\right)_{6}\right]\left[\mathrm{BF}_{4}\right]_{2}} \\
(5,0.015)\end{array}$ & $\begin{array}{l}\text { (5) } \\
(5,0.0083)\end{array}$ & $A B(10,0.32)$ & $(10,0.089)^{a}$ & $1: 6: 21$ & $\operatorname{THF}(5,62)$ & 22 & $0.62 / 1.61$ \\
\hline 14 & $\begin{array}{l}{\left[\mathrm{Fe}\left(\mathrm{H}_{2} \mathrm{O}\right)_{6}\right]\left[\mathrm{BF}_{4}\right]_{2}} \\
(5,0.015)\end{array}$ & $\begin{array}{l}\text { (R,R-6) } \\
(5,0.0083)\end{array}$ & $A B(10,0.32)$ & $(10,0.089)^{a}$ & $1: 6: 21$ & $\operatorname{THF}(5,62)$ & 22 & $1.08 / 1.43$ \\
\hline
\end{tabular}




\begin{tabular}{|c|c|c|c|c|c|c|c|c|}
\hline 15 & $\begin{array}{l}\text { (S,S-7) (9, } \\
0.0081)\end{array}$ & $\mathrm{N} / \mathrm{A}$ & $A B(10,0.32)$ & $(8,0.071)^{a}$ & $1: 9: 40$ & $\operatorname{THF}(5,62)$ & 22 & $0.28 / 0.71$ \\
\hline 16 & $\begin{array}{l}\mathrm{FeBr}_{2} \\
(2.75,0.013)\end{array}$ & $\mathrm{N} / \mathrm{A}$ & $A B(10,0.32)$ & $(10,0.089)^{a}$ & $1: 7: 25$ & $\operatorname{THF}(5,62)$ & 22 & $0.24 / 0.67$ \\
\hline 17 & $\begin{array}{l}\mathrm{FeBr}_{2} \\
(2.75,0.013)\end{array}$ & $\begin{array}{l}(5) \\
(5,0.0083)\end{array}$ & $A B(10,0.32)$ & $(10,0.089)^{a}$ & $1: 7: 25$ & $\operatorname{THF}(5,62)$ & 22 & $1.01 / 1.59$ \\
\hline 18 & $\begin{array}{l}\mathrm{FeBr}_{2} \\
(2.75,0.013)\end{array}$ & $\begin{array}{l}(5) \\
(10,0.016)\end{array}$ & $A B(10,0.32)$ & $(10,0.089)^{a}$ & $1: 7: 25$ & $\operatorname{THF}(5,62)$ & 22 & $1.03 / 1.53$ \\
\hline 19 & $\begin{array}{l}\mathrm{FeBr}_{2} \\
(2.75,0.013)\end{array}$ & $\begin{array}{l}\text { (5) } \\
(2.5,0.004)\end{array}$ & $A B(10,0.32)$ & $(10,0.089)^{a}$ & $1: 7: 25$ & $\operatorname{THF}(5,62)$ & 22 & $1.06 / 1.50$ \\
\hline 20 & $\begin{array}{l}\mathrm{FeBr}_{2} \\
(2.75,0.013)\end{array}$ & $\begin{array}{l}(5) \\
(1,0.002)\end{array}$ & $A B(10,0.32)$ & $(10,0.089)^{a}$ & $1: 7: 25$ & $\operatorname{THF}(5,62)$ & 22 & $1.11 / 1.58$ \\
\hline 21 & $\begin{array}{l}\mathrm{FeBr}_{2} \\
(2.75,0.013)\end{array}$ & $\begin{array}{l}(5) \\
(5,0.0083)\end{array}$ & $A B(10,0.32)$ & $(10,0.089)^{a}$ & $1: 7: 25$ & $\operatorname{THF}(5,62)$ & 2 & $0.87 / 1.24$ \\
\hline 22 & (1) $(7,0.0076)$ & $\mathrm{N} / \mathrm{A}$ & $A B(10,0.32)$ & $(8,0.071)^{a}$ & $1: 9: 42$ & $\begin{array}{l}\text { Diglyme } \\
(5,35)\end{array}$ & 22 & $1.06 / 1.44$ \\
\hline 23 & (2) $(7,0.0077)$ & N/A & $A B(10,0.32)$ & $(8,0.071)^{a}$ & $1: 9: 42$ & $\begin{array}{l}\text { Diglyme } \\
(5,35)\end{array}$ & 22 & $0.43 / 1.11$ \\
\hline 24 & (1) $(7,0.0076)$ & N/A & $\begin{array}{l}\mathrm{Me}_{2} \mathrm{AB}(20, \\
0.34)\end{array}$ & $(8,0.071)^{a}$ & 1:9:45 & $\operatorname{THF}(5,62)$ & 22 & $0.63 / 0.98$ \\
\hline 25 & (2) $(7,0.0077)$ & N/A & $\begin{array}{l}\mathrm{Me}_{2} \mathrm{AB}(20, \\
0.34)\end{array}$ & $(8,0.071)^{a}$ & $1: 9: 45$ & $\operatorname{THF}(5,62)$ & 22 & $0.44 / 0.96$ \\
\hline 26 & (1) $(7,0.0076)$ & $\mathrm{N} / \mathrm{A}$ & $A B(10,0.32)$ & $(16,0.14)^{\mathrm{a}}$ & $1: 18: 42$ & $\operatorname{THF}(5,62)$ & 22 & $1.33 / 1.83$ \\
\hline 27 & (1) $(7,0.0077)$ & $\mathrm{N} / \mathrm{A}$ & $A B(10,0.32)$ & $(4,0.035)^{a}$ & $1: 5: 42$ & $\operatorname{THF}(5,62)$ & 22 & $1.00 / 1.25$ \\
\hline 28 & (1) $(7,0.0077)$ & $\mathrm{N} / \mathrm{A}$ & $A B(10,0.32)$ & $(37,0.33)^{a}$ & $1: 43: 42$ & $\operatorname{THF}(5,62)$ & 22 & $1.17 / 1.66$ \\
\hline 29 & (1) $(7,0.0077)$ & $\mathrm{N} / \mathrm{A}$ & $A B(10,0.32)$ & $0^{c}$ & $1: 10^{c}: 42$ & $\operatorname{THF}(5,62)$ & 22 & $0.99 / 1.22$ \\
\hline 30 & $\begin{array}{l}\mathrm{FeBr}_{2} \\
(1.75,0.008)\end{array}$ & $\begin{array}{l}(5) \\
(3.0,0.005)\end{array}$ & $A B(10,0.32)$ & $(8,0.071)^{a}$ & $1: 9: 40$ & $\operatorname{THF}(5,62)$ & 22 & $0.98 / 1.43$ \\
\hline 31 & $\begin{array}{l}\mathrm{FeBr}_{2} \\
(1.75,0.008)\end{array}$ & $\begin{array}{l}(5) \\
(3.0,0.005)\end{array}$ & $A B(10,0.32)$ & $(8,0.071)^{a}$ & $1: 9: 40$ & $\begin{array}{l}\text { Diglyme } \\
(5,35)\end{array}$ & 22 & $1.11 / 1.39$ \\
\hline 32 & (1) $(7,0.0077)$ & $\mathrm{N} / \mathrm{A}$ & $A B(5,0.16)$ & $(6,0.053)$ & $1: 7: 21$ & $\operatorname{THF}(5,62)$ & $28^{d}$ & $\mathrm{~N} / \mathrm{A}$ \\
\hline 33 & $\begin{array}{l}\mathrm{FeBr}_{2} \\
(2.75,0.013)\end{array}$ & $\begin{array}{l}(5) \\
(2.5,0.04)\end{array}$ & $A B(7,0.22)$ & $(7,0.062)$ & $1: 5: 17$ & $\operatorname{THF}(5,62)$ & $28^{d}$ & $\mathrm{~N} / \mathrm{A}$ \\
\hline
\end{tabular}

${ }^{a}$ When the dry-addition flask is tilted and base added, 1 mg of KOtBu remains trapped in the flask, hence why an excess was always added. ${ }^{b} \mathrm{C}: \mathrm{B}: \mathrm{S}=$ molar ratio of catalyst:base:substrate $/ \mathrm{H}_{2}$ source. ${ }^{\mathrm{C}}$ Used $\mathrm{NaOiPr}(6 \mathrm{mg}, 0.073 \mathrm{mmol}) .{ }^{\mathrm{d}}$ Reactions done in a vial in an argon glovebox - solutions used for TEM imaging. 


\section{Results and Discussion}

AB Dehydrogenation with Precatalysts (1-4) in Protic Solvents. Following Xu et.al.'s work ${ }^{30}$ on the hydrolysis of $A B$ using $3 \mathrm{~nm}$ FeNPs, we were interested in applying our FeNP TH precatalysts (2) and (4) to the dehydrogenation of $A B$. The optimized method for the formation of FeNPs for our previously reported transfer hydrogenation catalysis was the reaction of an excess of KOtBu in iPrOH with precatalyst (2) or (4) before the addition of substrate. Therefore, for the dehydrogenation of $A B$ we first tested our precatalysts in protic solvents using a slightly modified technique as outlined in the experimental section. Using $2.5 \mathrm{~mol} \%$ precatalyst at $22^{\circ} \mathrm{C}(1-4)$ were tested as outlined in entries $1-4$ of Table 1 yielding the results shown in Figure 2. Several observations can be made from the plot; all four precatalysts are active and yield $>2.5$ equivalents of $\mathrm{H}_{2}$ in an hour. For $\mathrm{TH}$, a 6-8 minute induction period was observed for the formation of the FeNPs, whereas none of the reaction profiles in Figure 2 show this. An induction period is often indicative of heterogeneous catalysis, ${ }^{39,40}$ however, Xu et. al. also reported no induction period for their in situ generated system. Also of note, the bis-MeCN complexes (1) and (3) show a more rapid initial rate and a more rapid deactivation (plots level off at a lower number of equivalents of $\mathrm{H}_{2}$ ) than the corresponding MeCN-trans-CO complexes (2) and (4). The reason for this difference is unclear but it would suggest that the catalysts derived from the bis-MeCN precatalysts have more active sites available due to the increased lability of $\mathrm{MeCN}$ versus $\mathrm{CO}$. This increased lability would result in more rapid initial rates, and more ready deactivation. (3) and (4) are slightly more active than (1) and (2) indicating that the bulkier phenyl groups in the PNNP ligand are better stabilizers of the active species than the achiral complex with protons in the PNNP backbone of the ligand. ${ }^{11} \mathrm{~B} N M R$ spectrum of active solutions show a singlet at $18.2 \mathrm{ppm}$, corresponding to $\mathrm{B}(\mathrm{OiPr})_{3}$ as would be expected for reactions in $\mathrm{iPrOH}$.

Figure 2: Catalytic dehydrogenation of $A B(10 \mathrm{mg}, 0.32 \mathrm{mmol})$ in $5 \mathrm{~mL}$ iPrOH at $22^{\circ} \mathrm{C}$ using $2.5 \mathrm{~mol} \% \mathrm{Fe}$ and $20 \mathrm{~mol} \% \mathrm{KOtBu}$. Fe:AB:KOtBu = 1:40:8

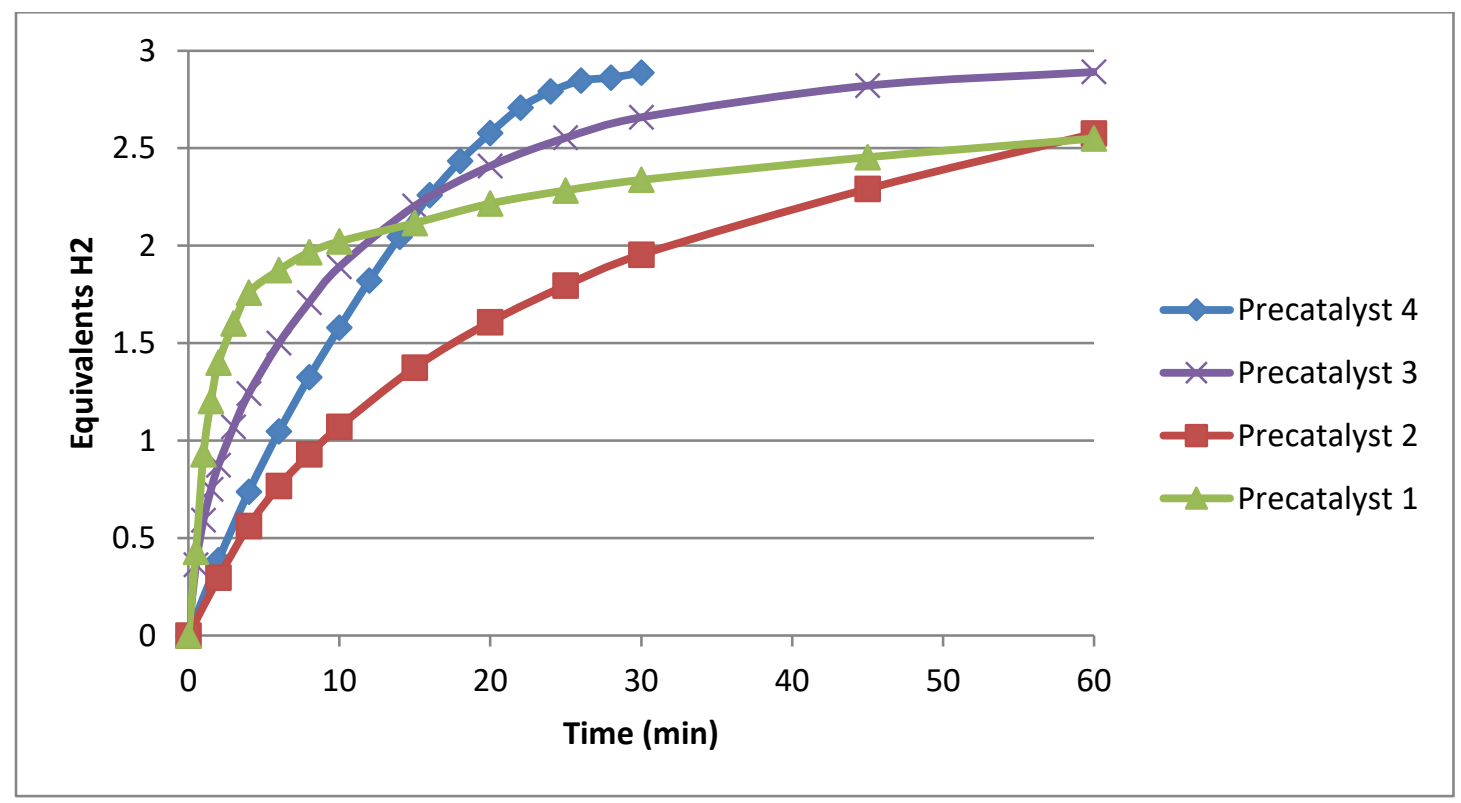

To test the reuse of our catalytic systems we added another 40 equivalents of $A B$ to the reaction mixtures after 30 min. Upon addition, (1-3) released $\sim 1$ equivalent $\mathrm{H}_{2}$ within 2 hours, indicating that the catalyst was significantly deactivated. Interestingly, addition of a second batch of $A B$ to catalysis with (4) resulted in 2.4 equivalents of $\mathrm{H}_{2}$ released in 40 minutes before deactivation occurred, and further 
recycling by addition of more $A B$ was unsuccessful. This would suggest that the active species derived from (4) is slightly better stabilized than the species derived from (1-3), but that all species are not good candidates for multiple recycles, unlike the species studied by Xu et. al. $^{30}$

We also explored the use of water and methanol as potential solvents. Only minimal activity was observed using (2) and (4) with $\mathrm{MeOH}$ as the solvent, and no activity was observed using (1-4) with water as the solvent. There is no hydrogen evolution if any component (Fe, base, $A B)$ is missing.

AB Dehydrogenation with Precatalysts (1-4, 7) in Non-Protic Solvents. We were interested in using our catalysts to generate $B-N$ polymers and oligomers from $A B$ using non-protic solvents such as THF and glyme. Using the same catalytic conditions as outlined with $\mathrm{PrOH}$, we tested THF as a solvent with (1-4) as outlined by entries 6, 10-12 of Table 1 and the results are shown in Figure 3. All four systems are highly active, releasing half an equivalent of $\mathrm{H}_{2}$ within seconds and a full equivalent in under a minute in the case of (1) and (3) and in less than 20 minutes for (2) and (4). Similar to the case in iPrOH, the bis$\mathrm{MeCN}$ catalysts are faster at $\mathrm{H}_{2}$ evolution than their MeCN-trans-CO counterparts. MeCN may be a more labile ligand than $\mathrm{CO}$ on iron nanoparticles, yielding a less stable species. This might yield a larger number of active sites in either a homogeneous or heterogeneous catalyst, and thus increase catalytic activity. This was not the case for $\mathrm{TH}$ as the one carbonyl ligand was necessary to promote catalytic activity. $^{32}(\mathbf{3})$ and (4) are slightly more active than (1) and (2) respectively, again suggesting the added stabilization of the catalysts containing the bulkier diphenyl backbone in the PNNP ligand versus the achiral PNNP which contains only protons in the backbone. All of the catalytic systems also show a similar reaction profile, whereby there is very rapid catalytic activity in the first 3 minutes, followed by a significant decrease in rate resulting in very slow $\mathrm{H}_{2}$ evolution for the proceeding hour. This reaction profile for dehydrogenation of amine-boranes is fairly common, as has been seen for both heterogeneous NP catalysis ${ }^{25}$ as well as homogeneous catalysis, specifically the $\mathrm{Ru}(\mathrm{PN})_{2}$ alcohol oxidation/reduction catalysts tested by Blaquiere et.al. ${ }^{11}$ There are two possible explanations for this rapid decrease in activity; first, that all of the $A B$ has been consumed and converted into the most stable product. This is not the case because $A B$ is still present according to ${ }^{11} \mathrm{~B} N M R$ (vide infra) and because addition of more $A B$ yields no further $\mathrm{H}_{2}$ evolution. This therefore indicates that the cause for the rate decrease is deactivation of the catalyst. Baker et. al. observed that, upon catalyst deactivation with their system, a black residue of bulk iron was formed; ${ }^{7}$ however this is not observed with our systems. They also observed protonation of their amide ligands and formation of P-B adducts with their phosphine ligands, which we did not observe in the ${ }^{11} \mathrm{~B} N M R$. Instead the primary species observed with ${ }^{31} \mathrm{P}\left\{{ }^{1} \mathrm{H}\right\}$ NMR is de-coordinated PNNP ligand at $-16 \mathrm{ppm}$. A similar spectrum was observed with the activated solution in $\mathrm{TH}^{33}$ when some of the PNNP ligand de-coordinated to allow for formation of FeNPs. The release of PNNP ligand and the observation that no bulk iron is released supports that FeNPs are forming during catalysis and that deactivation involves blocking of active sites on the NP surface, potentially by reactive B-N compounds. Further discussion of deactivation modes on iron will be discussed vide infra. Also depicted in Figure 3 is the reaction profile using precatalyst $(\mathrm{S}, \mathrm{S})$ $\left[\mathrm{Fe}(\mathrm{CO})(\mathrm{Br})\left(\mathrm{PPh}_{2} \mathrm{CH}_{2} \mathrm{CH}=\mathrm{NHCHPh}\right)_{2}\right]\left[\mathrm{BPh}_{4}\right]$ (7) (entry 15 of Table 1). This precatalyst is a highly active $\mathrm{TH}$ system also developed in our group ${ }^{38,41}$ that was recently studied mechanistically ${ }^{42}$ and determined to likely operate via a homogeneous mechanism, as there are no low energy pathways leading to $\mathrm{Fe}(0) .{ }^{43}$ This system is much less active than systems (1-4), supporting that the systems operate via different mechanisms for the dehydrogenation of $A B$, also suggesting that precatalysts (1-4) may generate FeNPs during catalysis. 
Figure 3: Catalytic dehydrogenation of $A B(10 \mathrm{mg}, 0.32 \mathrm{mmol})$ in $5 \mathrm{~mL}$ THF at $22^{\circ} \mathrm{C}$ using $2.5 \mathrm{~mol} \%$ Fe and $20 \mathrm{~mol} \% \mathrm{KOtBu}$

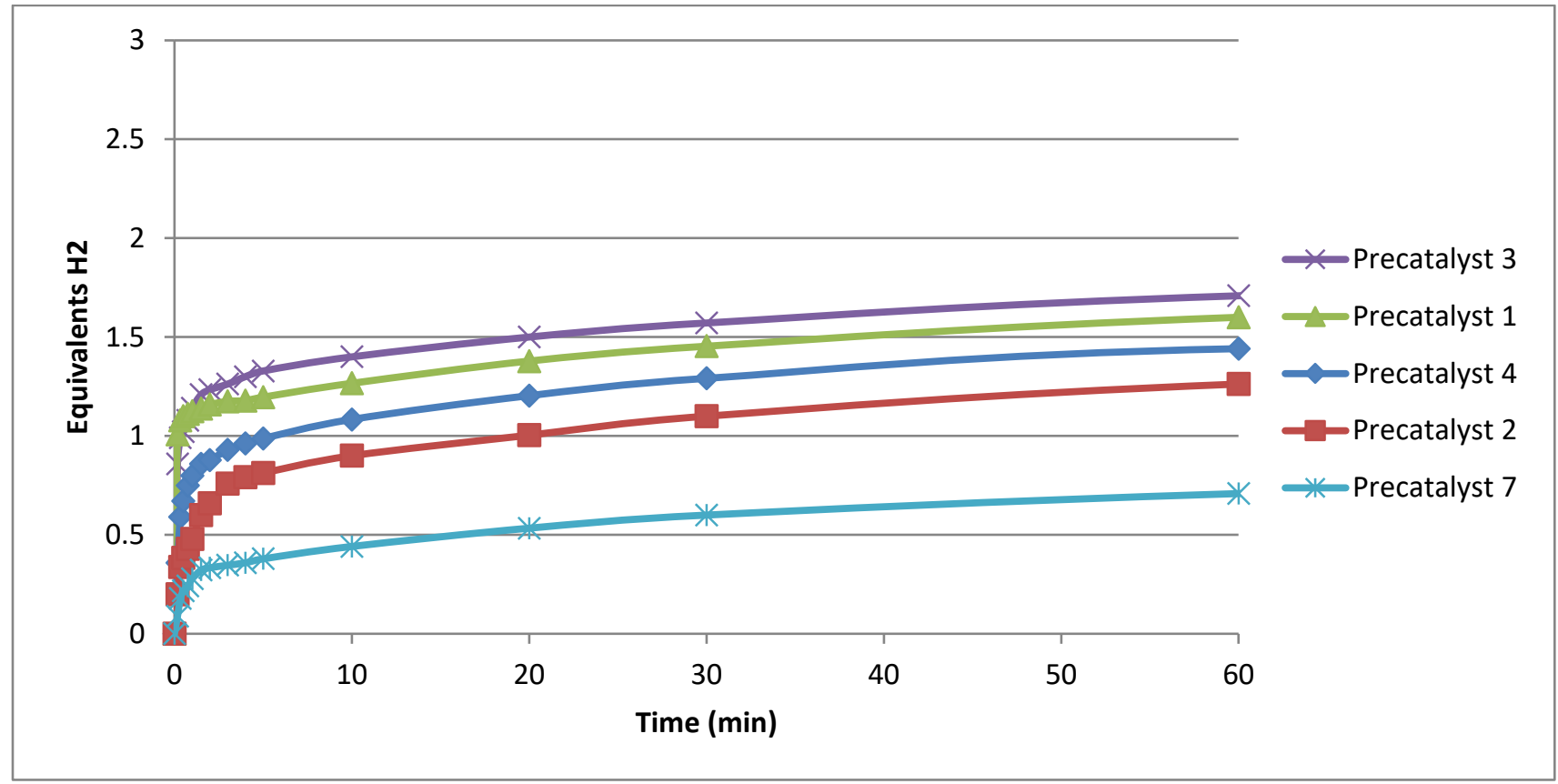

${ }^{11} B\left\{{ }^{1} \mathrm{H}\right\}$ NMR spectrum of the activated solutions using (1) contained some peaks for some unreacted $A B$ and four major species at 20.3, 24.3, 27.8 and $30.9 \mathrm{ppm}$. Upon coupling to protons, the peaks at 27.8 and 30.9 split into doublets with coupling constants of $137 \mathrm{~Hz}$ and $132 \mathrm{~Hz}$ respectively, indicating two different $\mathrm{B}-\mathrm{H}$ groups and two different unprotonated boron sites are present. The peak at $30.9 \mathrm{ppm}$ is assigned to be borazine, ${ }^{9}$ and the remaining coupled and uncoupled boron species are tentatively assigned as polyborazylene (PB) and short chain B-N oligomers or partially cross-linked polyborazylene which could not be isolated or identified further. ${ }^{11} \mathrm{~B}$ NMR spectrum of the activated solutions using (2) also contained unreacted $A B$, a triplet at $-10 \mathrm{ppm}$ for cyclotriborazane $(\mathrm{CTB})^{7,9}$ and two doublets at 30.9 and 27.9 as observed with (1). This correlates with the fact that (1) generates more $\mathrm{H}_{2}$ than (2), in agreement with the formation of some PB versus CTB.

The difference in activity of (1) and (2) versus (3) and (4) was small, and therefore the use of the more expensive, chiral catalysts bearing the diphenyl backbone was discontinued and further experiments were only conducted using (1) and (2).

Due to the highly solvent dependent nature of these systems whereby there is no hydrogen evolution in water, slow but continuous evolution in $\mathrm{PrOH}$ and rapid activity in THF, we also tested diglyme as a dehydrogenation solvent (Entries 22-23, Table 1) Reaction profiles using both (1) and (2) in THF were compared to profiles of reactions done in diglyme and the plots were the same, within error. This suggests that the same active species is generated in both solvents.

Effect of Varying Conditions of AB Dehydrogenation with Precatalyst (1). Following optimizations of the solvent and precatalyst, we chose to further evaluate (1) under varying conditions to probe its robustness. We first probed the catalytic system for its temperature dependence. Standard reactions are run at $22^{\circ} \mathrm{C}$, so we tested the activity of the system when it was pre-cooled using an ice bath (entry 7, Table 1) The reaction profile is depicted in Figure 4 and shows that although the activity is decreased slightly when compared to runs at $22^{\circ} \mathrm{C}$, the system is still quite active, evolving one equivalent $\mathrm{H}_{2}$ in 2 minutes, and 1.4 equivalents in an hour before deactivating, compared to 1 equivalent $\mathrm{H}_{2}$ in less than 30 
seconds and 1.6 equivalents in an hour for the reaction at $22^{\circ} \mathrm{C}$. The decrease in initial rate can be attributed to slower activation at lower temperatures, but the overall high efficiency of the system at $2^{\circ} \mathrm{C}$ reflects how unique these systems are when compared to the majority of other $A B$ dehydrogenation catalysts that require high temperatures. ${ }^{10,14,25}$ Due to the difference in activity observed between the bis-MeCN and MeCN-trans-CO precatalysts, we were interested in the effect $\mathrm{CO}$ gas would have on the activity of the catalysts (entry 8 , Table 1 ). When reactions were run under a CO headspace instead of an argon headspace, minimal $\mathrm{H}_{2}$ evolution was observed, as shown in Figure 4. This would suggest that either active species are forming and are immediately poisoned by $\mathrm{CO}$, or $\mathrm{CO}$ inhibits the formation of active species. Due to the fact that there is no initial activity observed, it is likely that the active species do not form under these conditions. To further probe this, we attempted to poison the system after activation with a known amount of $\mathrm{CO}$; however the results were inconclusive because the reaction setup employs an open system and the $\mathrm{CO}$ gas was rapidly purged by the evolving hydrogen.

We were also interested in testing the limits of the catalyst at much higher AB loadings to see if our systems could compare to the highly rapid ruthenium systems developed by Schneider ${ }^{15}$ and Fagnou ${ }^{11}$. Using 0.83 mol\% (1) (Fe:AB = 1:120 instead of Fe:AB = 1:40) (entry 9,Table 1) we observed the same general reaction profile, releasing one equivalent of $\mathrm{H}_{2}$ in under one minute, as shown in Figure 4. Using the linear portion of the plot (the first 30 seconds) the turnover frequency (TOF) can be calculated:

TOF $=\frac{n_{H 2}}{t \times n_{F e}}=\frac{\text { slope }}{n_{F e}}=3.66 s^{-1}$

Although the TOF is exceptionally high, the overall turnover number (TON) is only $154 \mathrm{H}_{2}$ per Fe due to catalyst deactivation.

Figure 4: Catalytic dehydrogenation of $A B$. Standard Run: $A B(10 \mathrm{mg}, 0.32 \mathrm{mmol})$ in $5 \mathrm{~mL}$ THF at $22^{\circ} \mathrm{C}$ using $2.5 \mathrm{~mol} \%$ Precatalyst (1) and 20 mol\% KOtBu, Fe:AB:KOtBu = 1:40:8. Variations from standard conditions as listed in legend.

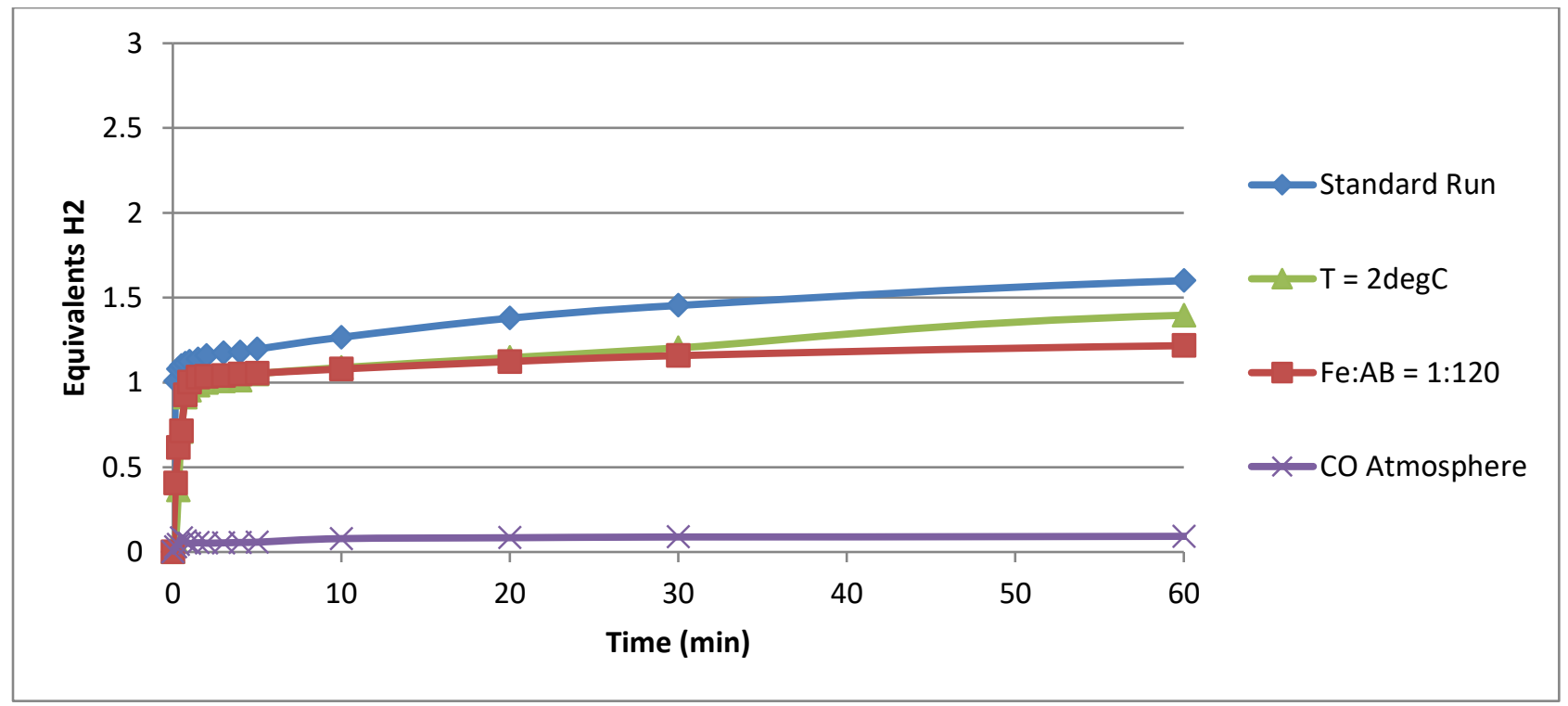

Standard experiments were done using 8 equivalents of KOtBu as the base, relative to iron, and we were interested in probing the dependence of catalytic activity on base and therefore ran experiments using both double (16 equivalents - entry 26) and half ( 4 equivalents - entry 27, Table 1) the amount of base, and the reaction profiles are depicted in Figure 5. As would be expected, all three profiles (standard run, and half and double KOtBu) show the same general shape with rapid initial activity followed by a significant rate decrease as the catalyst deactivates; however the initial rate with half base is slower and 
the overall $\mathrm{H}_{2}$ production varies between all three sets of experiments. The slower initial rate with 4 equivalents of base versus 8 or 16 ( 1 equivalent $\mathrm{H}_{2}$ in 45 seconds for half base versus 10 seconds for both 8 and 16 equivalents) can be attributed to slower activation with a lower concentration of base. More surprisingly was the overall yield of $\mathrm{H}_{2}$ achieved by varying the concentration of base; $1.83,1.60$ and $1.25 \mathrm{H}_{2}$ in one hour for 16, 8 and 4 equivalents of base (relative to (1)) respectively. Given the similar reaction profiles and same initial rates for 8 and 16 equivalents KOtBu, it would appear as though catalyst activation is occurring in all cases. It is possible that deactivation of the catalyst is minimized under the more basic conditions, as alkoxides could protect the active sites; however the exact reason is still unclear. To probe this, we thought that perhaps the base was reacting stoichiometrically with boron-containing intermediates, allowing for more equivalents to be released when more base was present. We were able to rule this out, as running the reaction with equimolar amounts of KOtBu and $A B$ (entry 28, Table 1 ) we did not evolve more $\mathrm{H}_{2}$ than with 40 mol\% KOtBu. Rather, we saw a decrease in overall yield ( 1.66 equivalents $\mathrm{H}_{2}$ in 1 hour in comparison to 1.83), indicating that too much base has the opposite effect, and that the base dependence of this system is much more complicated. To complete our base dependence studies, we tested the use of NaOiPr, as it is both reducing and basic, albeit less basic than KOtBu. KOtBu is a very strong base but is not reducing, whereas NaOiPr is a weaker base but is a moderately strong reductant. Using the standard 20 mol\% NaOiPr (entry 29, Table 1) we observed that the system was much less active, both in terms of initial rates and overall $\mathrm{H}_{2}$ evolution, as depicted by the green plot in Figure 5. Therefore reduction of iron occurs most rapidly in the presence of $A B$ and the stronger base.

Figure 5: Catalytic dehydrogenation of $A B$. Standard Run: $A B(10 \mathrm{mg}, 0.32 \mathrm{mmol})$ in $5 \mathrm{~mL}$ THF at $22^{\circ} \mathrm{C}$ using $2.5 \mathrm{~mol} \%$ Precatalyst (1) and base.

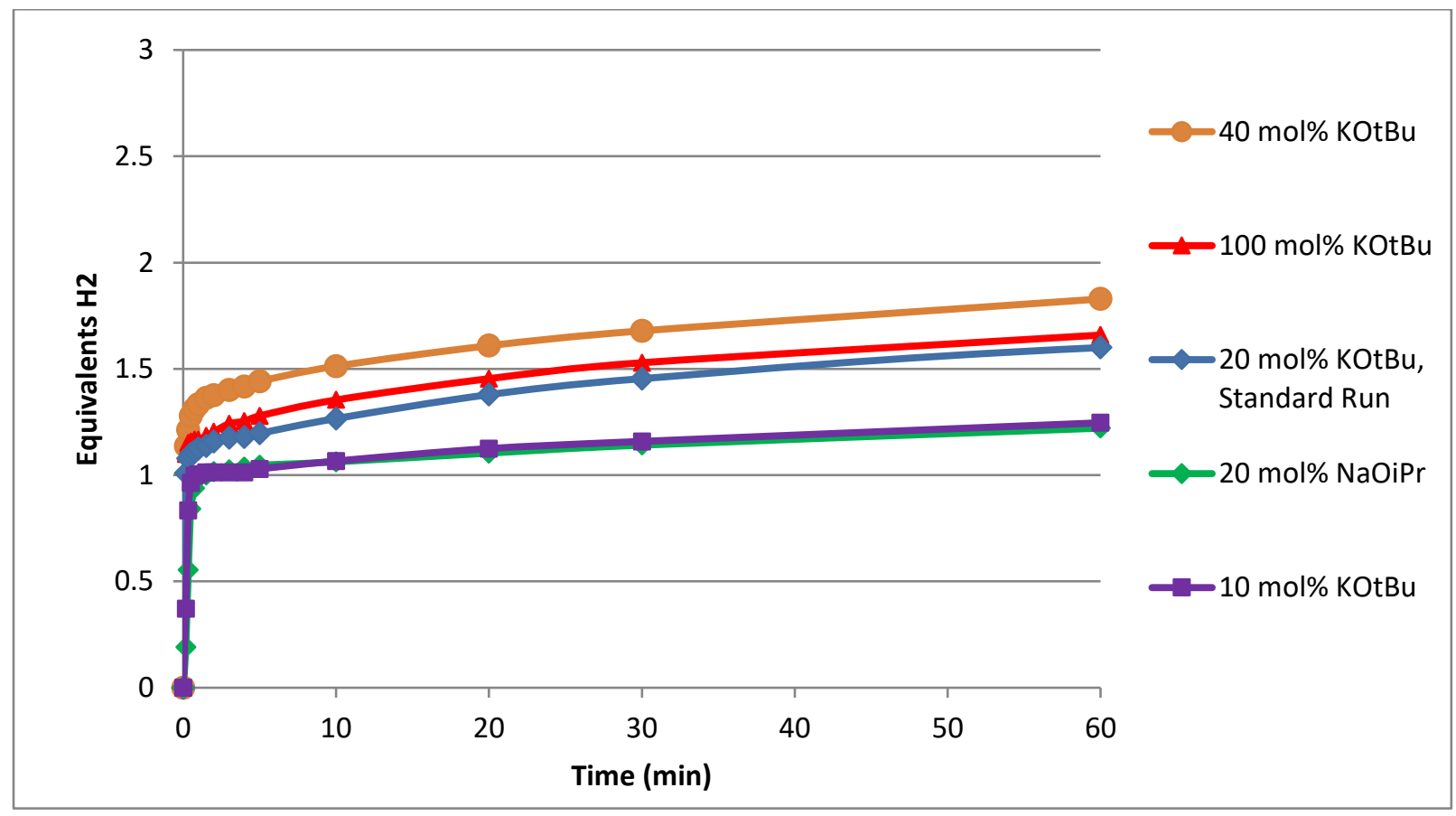

Finke has reported that the formation of nanoparticles for use in catalysis can be viewed as an autocatalytic process ${ }^{44}$ whereby precatalyst forms active NP catalyst, which then auto-catalyses the formation of more active catalyst. From this we would expect that at very low precatalyst concentrations formation of NPs would be significantly slower and that an induction period might occur. To test the dependence of catalysis on iron concentration, we varied the concentration of (1) in 
otherwise identical reaction conditions. Precatalyst concentrations of $1.5,0.65$ and $0.15 \mathrm{mM}$ were tested. 1.5 and $0.65 \mathrm{mM}$ yielded similar reaction profiles with rapid initial activity followed by deactivation, however the initial rate using $0.65 \mathrm{mM}$ precatalyst was approximately $75 \%$ that of the standard $1.5 \mathrm{mM}$ run. Dropping the concentration of precatalyst lower to $0.15 \mathrm{mM}$ yielded a completely different profile exhibiting a 10 second induction period, followed by rapid catalytic activity then deactivation. This non-first order kinetics is to be expected for NP formation as at very low iron concentrations nucleation and growth of NPs is expected to be significantly slower.

AB Dehydrogenation with In Situ Generated Catalysts. Further optimization of our catalytic systems led to an investigation of in situ generated catalysts that would preclude the necessity to first generate our FePNNP precatalysts. This involved using a one pot reaction of commercially available Fe(II) precursors, $\mathrm{KOtBu}, \mathrm{AB}, \mathrm{PNNP}-$ ligand and solvent. We previously calculated that for the $4 \mathrm{~nm}$ FeNPs derived from (2) and (4) for TH that approximately $50 \%$ of the iron would be on the surface, ${ }^{34}$ indicating that less than half of the ligand was being used. We therefore ran initial tests using Fe(II) precursors and 0.6 equivalents of PNNP-ligand. $\left[\mathrm{Fe}\left(\mathrm{H}_{2} \mathrm{O}\right)_{6}\right]\left[\mathrm{BF}_{4}\right]_{2}$ was tested with ligand (5) from Figure 1 , the same PNNP ligand of (1) and (2), in iPrOH (entry 5) and THF (entry 13, Table 1) for AB dehydrogenation using 4 mol\% Fe (relative to $A B$ ). In $\mathrm{PrOH}$ the reaction rate was much slower than the preformed catalysts, yielding only one equivalent of $\mathrm{H}_{2}$ in just under an hour before the system deactivated. In THF, the in situ generated catalyst showed comparable activity in terms of initial rates and overall $\mathrm{H}_{2}$ generation to reactions using (1), at a lower $A B$ loading, suggesting that the same active species is being formed. To further investigate ligand effects we synthesized bulkier and more basic PNNP ligand (6) as shown in Figure 1 which contains a cyclohexyl diamine backbone (entry 14, Table 1) and compared activity with ligand (5) and the reaction profiles are shown in Figure 6. Reaction profiles with both ligands are the same in terms of initial rates and extent of $\mathrm{H}_{2}$ evolution indicating that making this steric and electronic change had a negligible effect. This was to be expected as catalysis with (1) versus (3) is also similar in THF. We were also interested in the effect of different Fe(II) precursors and therefore tested $\mathrm{FeBr}_{2}$ (entry 17, Table 1) The overall reaction profile in Figure 6 is the same for both $\left[\mathrm{Fe}\left(\mathrm{H}_{2} \mathrm{O}\right)_{6}\right]\left[\mathrm{BF}_{4}\right]_{2}$ and $\mathrm{FeBr}_{2}$ metal precursors, once again suggesting that the same active species is being formed. Both yield the same final amount of $\mathrm{H}_{2}$ (1.6 equivalents in $1 \mathrm{hr}$ ) although $\mathrm{FeBr}_{2}$ shows a slightly more rapid initial activation, potentially due to improved solubility or more rapid reduction to NPs. To confirm that the activity of $\mathrm{FeBr}_{2}$ with (5) can be compared to reactions with (1), we also ran reactions using the same substrate loading (Fe:AB =1:40) as outlined in entry 30 of Table 1 and depicted in Figure 6 . Similar initial rates and extent of $\mathrm{H}_{2}$ evolution at both 1:25 and 1:40 was observed, allowing direct comparisons to be made with (1); (1) yields 1.1 equivalents $\mathrm{H}_{2}$ in 30 seconds, and $1.6 \mathrm{in} 1 \mathrm{hr}$, whereas $\mathrm{FeBr}_{2}$ with (5) yields 1 equivalent in 30 seconds and $1.4 \mathrm{in} 1 \mathrm{hr}$, strongly suggesting the same active site is present in both. Experiments in diglyme (entry 31, Table 1) the same results as catalysis in $\mathrm{THF}$ for the $\mathrm{FeBr}_{2}$ with (5) system, as was observed with (1) and (2). Manners et. al. recently reported the use of skeletal nickel heterogeneous catalysts derived from the selective leaching of aluminum out of a 50/50 Ni/Al alloy for the dehydrogenation of amine-boranes. ${ }^{29}$ Although the nickel systems were quite active, similarly prepared iron systems were inactive, suggesting the subtle interplay of metal and stabilizing ligand in our systems which allow them to be so active. 
Figure 6: Catalytic dehydrogenation of $A B(10 \mathrm{mg}, 0.32 \mathrm{mmol})$ in $5 \mathrm{~mL}$ THF at $22^{\circ} \mathrm{C}$ using 4 or $2.5 \mathrm{~mol} \% \mathrm{Fe}, 2.6$ or $1.6 \mathrm{~mol} \%$ ligand and 32 or 20 mol\% KOtBu. Fe:Ligand:AB:KOtBu $=1: 0.6: 25: 8$ or 1:0.6:40:8. Where Fe-H2O $=\left[\mathrm{Fe}\left(\mathrm{H}_{2} \mathrm{O}\right)_{6}\right]\left[\mathrm{BF}_{4}\right]_{2}$

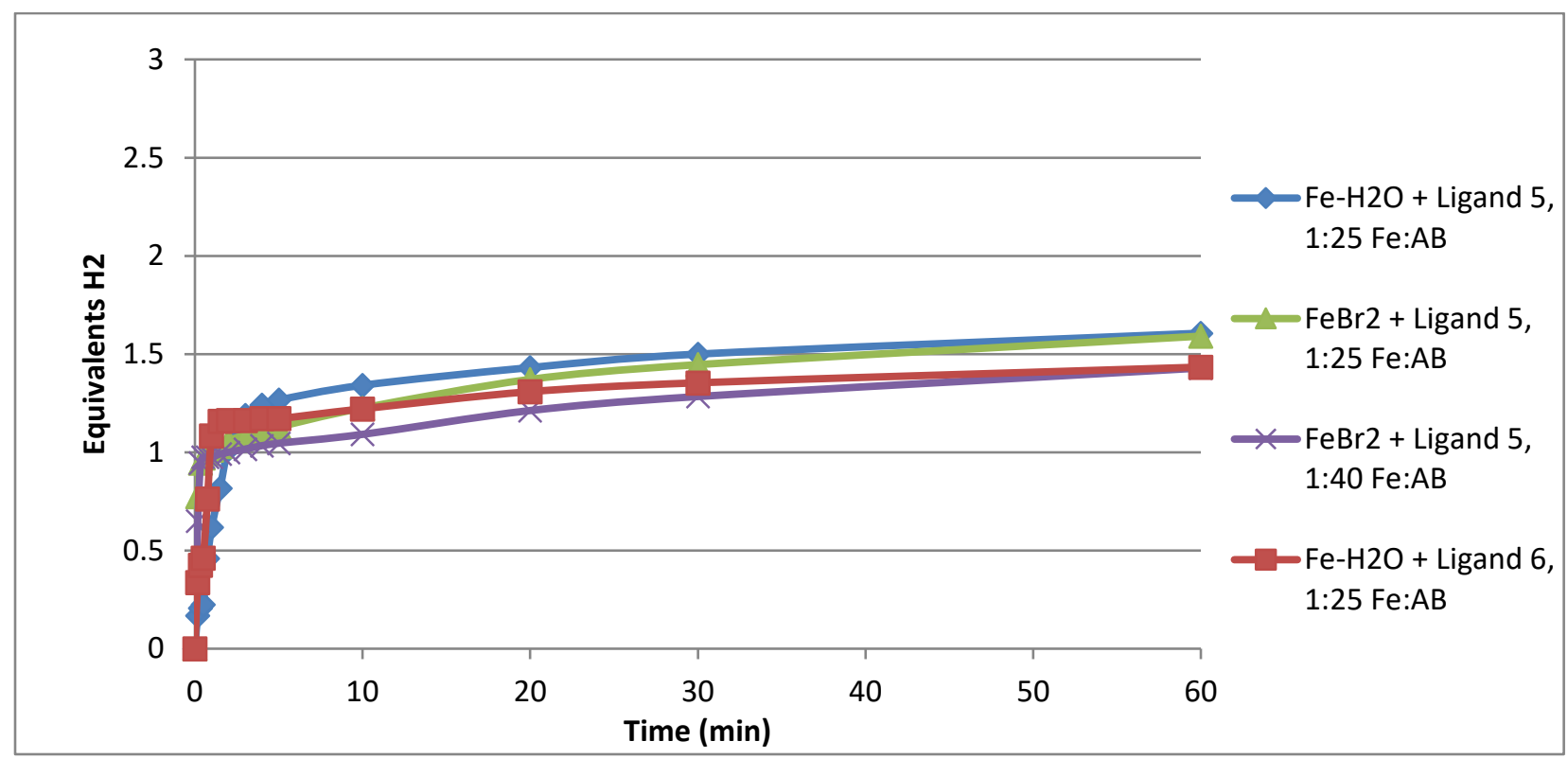

${ }^{11} \mathrm{~B} N M R$ analysis of in situ solutions of catalysis with $\left[\mathrm{Fe}\left(\mathrm{H}_{2} \mathrm{O}\right)_{6}\right]\left[\mathrm{BF}_{4}\right]_{2}$ and 0.5 equivalents of ligand showed two doublets at 30.9 and 27.8 with coupling constants of $127 \mathrm{~Hz}$ and $138 \mathrm{~Hz}$ respectively. The major species is the doublet at $27.8 \mathrm{ppm}$, and it appears to have a broad shoulder from 27 to $24 \mathrm{ppm}$. These peaks correspond closely with those previously observed using (1), although the singlets at 20.3 and $24.3 \mathrm{ppm}$ were not distinguishable. No peaks for free $A B$ were observed, therefore one would predict from the distribution of products that more than 1.6 equivalents of $\mathrm{H}_{2}$ should have been produced, supporting the theory that deactivation may be caused by binding of reactive B-N intermediates to the active sites of FeNPs, thereby poisoning the catalyst surface. This deactivation mechanism has been previously postulated by Manners et.al. on colloidal nickel catalysts. ${ }^{29}$ Binding of these species to the surface would make them undetectable by ${ }^{11} \mathrm{~B}$ NMR as the NPs would be superparamagnetic. ${ }^{34}$

Using $\mathrm{FeBr}_{2}$ and ligand (5), we further probed the temperature dependence of the system by running the reaction at $2^{\circ} \mathrm{C}$ as we had done previously with (1) (entry 21 , Table 1 ). Similar to the behaviour reported with (1), the plot at $2^{\circ} \mathrm{C}$ shows a similar overall shape as the plot at $22^{\circ} \mathrm{C}$ with a slightly slower initial rate, and a deactivation after fewer equivalents $\mathrm{H}_{2}$ released $\left(1.2\right.$ equivalents $\mathrm{H}_{2}$ at $2^{\circ} \mathrm{C}$ instead of 1.6 at $22^{\circ} \mathrm{C}$ ). As a second probe to compare the in situ generated catalyst to preformed catalyst we tested $\mathrm{FeBr}_{2}$ and ligand (5) for dehydrogenation of $\mathrm{AB}$ under an atmosphere of $\mathrm{CO}$. As was observed with (1), no hydrogen evolution was observed when the catalyst was generated under a CO atmosphere, indicating that $\mathrm{CO}$ impedes catalyst formation in both cases.

Chaudret et al. previously reported ${ }^{26}$ a dependence on metal to ligand ratio using their $\mathrm{Ru}^{0} \mathrm{NPs}$ stabilized by 3-aminopropyltriethoxysilane on the initial rates of dehydrogenation of dimethylamineborane (DMAB). We therefore investigated our $\mathrm{FeBr}_{2}$ system with different ratios of ligand (5) to determine the effect on stability (extent of conversion prior to deactivation) and initial rates. Figure 7 shows plots of experiments run using 1.2, 0.6, 0.3 and 0.15 equivalents of ligand (5), relative to $\mathrm{FeBr}_{2}$ (Entries 17-20, Table 1). Plots of 1.2, 0.6, 0.3 and 0.15 equivalents of ligand all show the same initial rates of overall conversion, and identical plot shape, yielding 1 equivalent of $\mathrm{H}_{2}$ in 1 minute 
and 1.6 equivalents in 1 hour. In contrast, the plot shown in green (triangles) represents the addition of no ligand (entry 16, Table 1), and exhibits significantly different behaviour. When there is no ligand present, activation is much slower and deactivation occurs much more rapidly, indicating that the ligand provides stabilization on the NP surface preventing agglomeration and active site poisoning. This also suggests that as little as 0.15 equivalents of ligand is required to give the needed stabilization to maximize efficiency of the catalyst. If the catalyst was homogeneous, one would expect to need equimolar amounts of iron and ligand, and that activity would decrease with decreasing ligand amount, however this is not the case. Further reduction of the amount of ligand yielded irreproducible results and overall decreased activity, indicating that 0.15 equivalents is the minimum amount of ligand necessary for this system. It is interesting that with changing ligand concentration there is no observable effect on the rate of catalysis. Chaudret ${ }^{26}$ observed that with too little ligand present larger, less active NPs formed, and this is likely the case with our system, which supports that when $<0.15$ equivalents of ligand are used irreproducible results are obtained. Chaudret also observed that with more ligand present the rate also decreased due to the excess of ligands binding to the active sites. In our system no rate decrease is observed with excess ligand, suggesting that the ligand does not act as an active site poisoning agent, likely because it is fairly bulky. This provides very strong evidence for a heterogeneous system as the active catalyst.

Figure 7: Catalytic dehydrogenation of $A B(10 \mathrm{mg}, 0.32 \mathrm{mmol})$ in $5 \mathrm{~mL}$ THF at $22^{\circ} \mathrm{C}$ using $4 \mathrm{~mol} \% \mathrm{FeBr}_{2}$, ligand (5) and $32 \mathrm{~mol} \%$ KOtBu (relative to AB). Fe:AB:KOtBu = 1:25:8

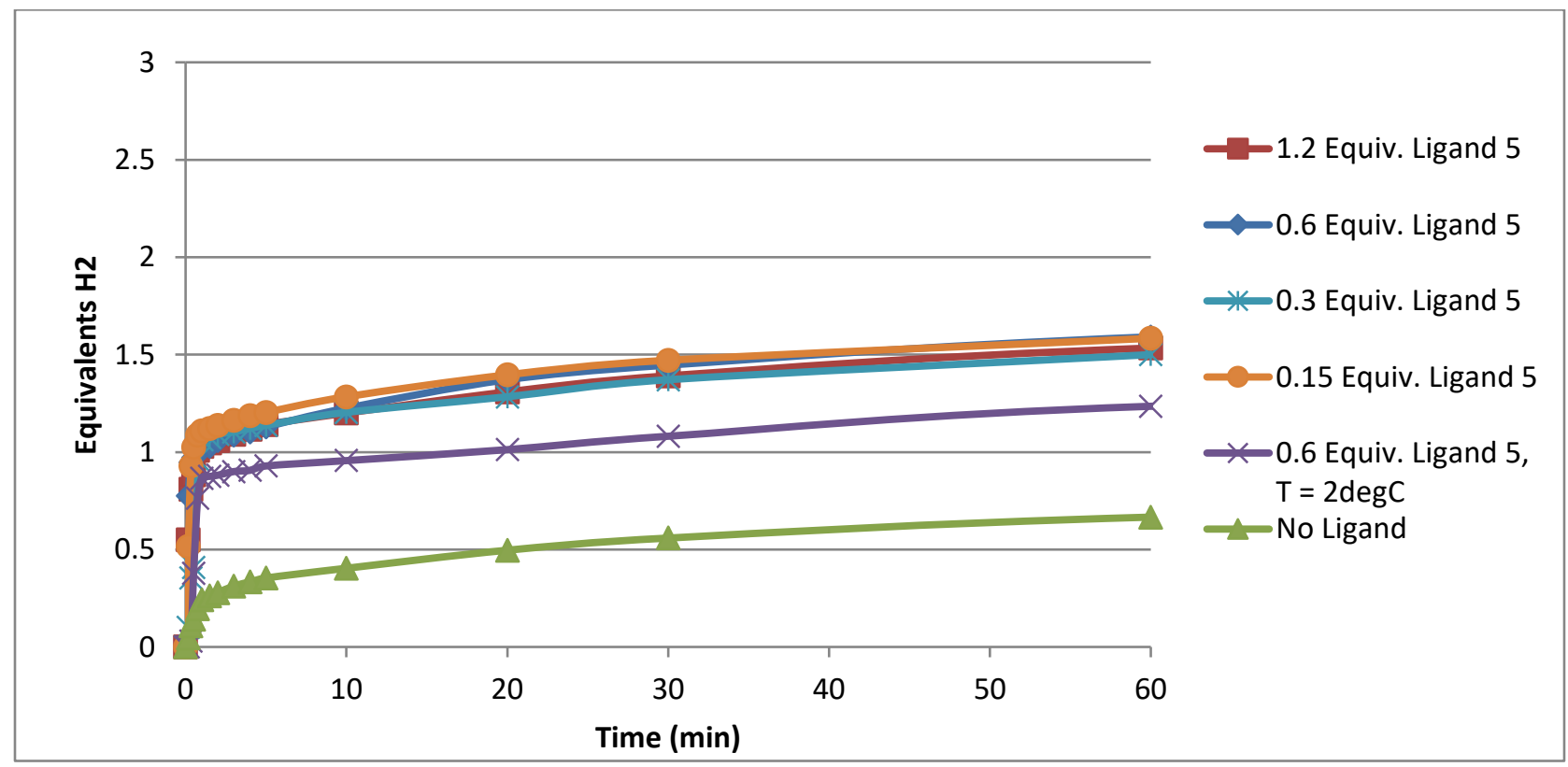

Dimethylamine-borane (DMAB) Dehydrogenation with Precatalysts (1-2). Many heterogeneous precious metal catalysts reported focus primarily on the dehydrogenation of DMAB instead of $A B, 16,24,26,28,29,45$ and thus we sought to test our systems using (1) and (2) with KOtBu in THF (Entries 2425 , Table 1). Using the same reaction conditions as employed with $A B$, and with similar catalyst loading (Fe:KOtBu:DMAB = 1:8:45) hydrogen evolution was measured at $22^{\circ} \mathrm{C}$. (1) and (2) yielded similar results with (1) achieving faster initial rates (0.62 equivalents $\mathrm{H}_{2}$ in 1 minute for (1) and 0.44 for (2)) but both catalysts yielded 0.97 equivalents $\mathrm{H}_{2}$ in 1 hour and 1.1 equivalents in 2 hours before deactivation. Similar to the $A B$ plots, dehydrogenation of DMAB shows a rapid initial $\mathrm{H}_{2}$ evolution, followed by a significant decrease in rate, before complete deactivation of the active species. Addition of more DMAB yielded no further $\mathrm{H}_{2}$ evolution indicating that catalyst deactivation had occurred, similar to the case with $A B .{ }^{11} B$ 
NMR analysis of the reaction solutions proved to be much more complicated than the $A B$ case and results are depicted in Figure 8. There is a sharp quartet at -13.3 for unreacted $D M A B$, a triplet at 2.8 and a quartet at -9.7 for the adduct $\mathrm{Me}_{2} \mathrm{NHBH}_{2} \mathrm{NMe}_{2} \cdot \mathrm{BH}_{3}$, a small triplet at 5.5 for the $\left(\mathrm{Me}_{2} \mathrm{~N}-\mathrm{BH}_{2}\right)_{2}$ heterocycle, which is typically the most common product formed during these reactions as it is the rapid decomposition product of the postulated $\mathrm{Me}_{2} \mathrm{~N}=\mathrm{BH}_{2}$ intermediate. ${ }^{16,21,29} \mathrm{NMR}$ also shows two doublets at 27 and 28.9 with couplings of 140 and $131 \mathrm{~Hz}$ respectively identified as $\mathrm{BH}\left(\mathrm{NMe}_{2}\right)_{2}$ and a second $\mathrm{BH}$ complex. ${ }^{22}$ Given the formation of $\mathrm{BH}\left(\mathrm{NMe}_{2}\right)_{2}$ it is likely that $\mathrm{BH}_{3}$ release occurs, which could interact with ${ }^{-} \mathrm{OtBu}$ in solution to generate $\mathrm{BH}(\mathrm{OtBu})_{2},{ }^{46,47}$ resulting in the doublet found at $28.9 \mathrm{ppm}$. Given the product distribution, one would surmise that evolution of a full equivalent of $\mathrm{H}_{2}$ would be unlikely, suggesting that some boron containing products may be insoluble or bound to a superparamagnetic NP, making them undetectable by NMR. This wide range of products and modest yields would suggest that the catalyst is not selective upon reaction with DMAB, nor is it competitive with other reported catalysts, but it is a useful proof of concept for these iron systems and their versatility.

Figure 8: In situ ${ }^{11} \mathrm{~B}$ NMR (128MHz) of catalytic dehydrogenation of $\mathrm{Me}_{2} \mathrm{NHBH}_{3}$ (entry 24 of Table 1) after 30min. Fe:B:KOtBu $=1: 45: 8$

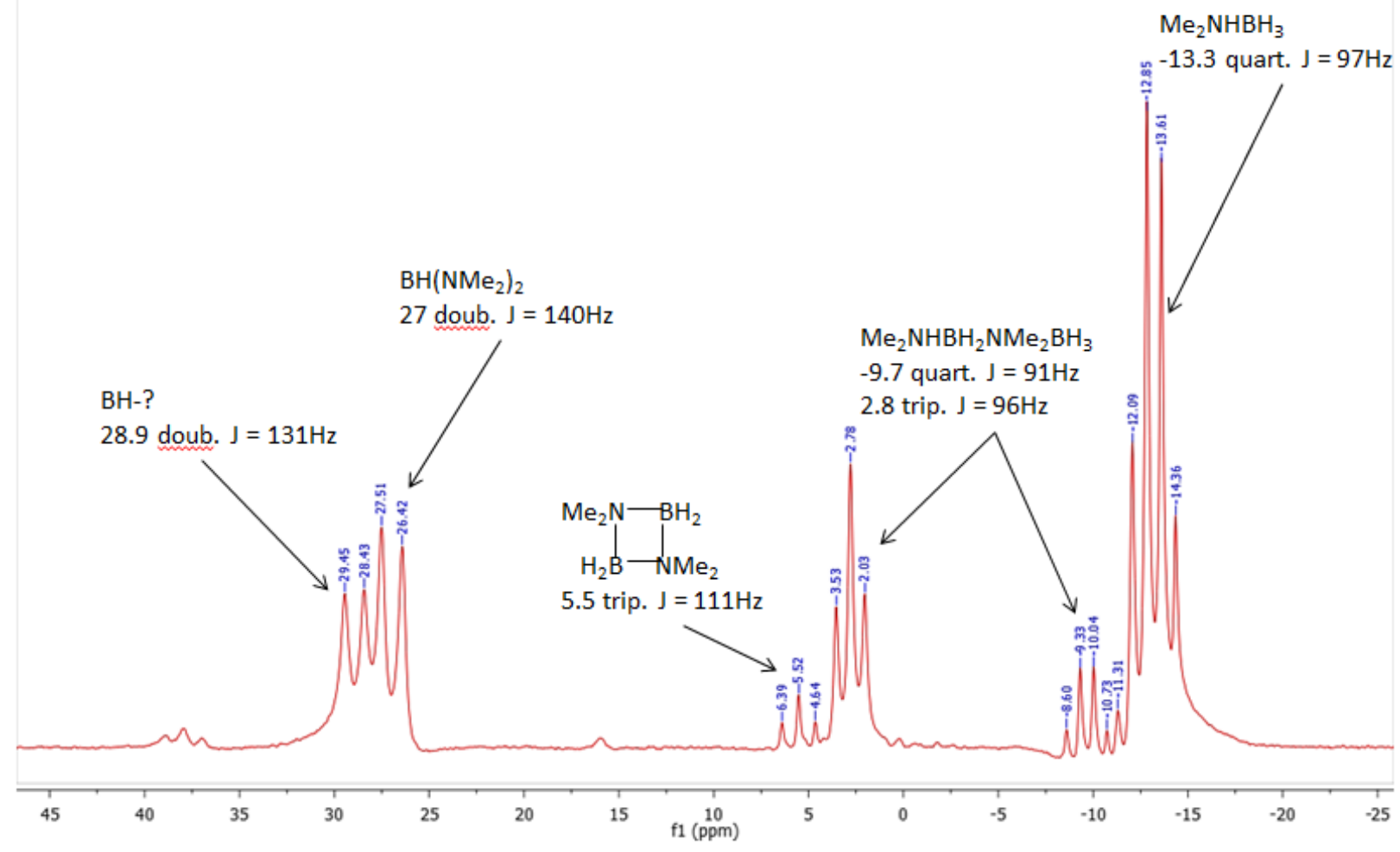

Electron Microscopy Imaging. To further probe the nature of our iron catalytic systems we investigated reaction solutions by transmission electron microscopy (TEM). We analysed reaction solutions of catalysis with (1) and of catalysis with $\mathrm{FeBr}_{2}$ with 0.3 equivalents of (5) as outlined in entries 28 and 29 respectively of Table 1. Figure 9 [left] is a standard image observed for catalysis with $\mathrm{FeBr}_{2}$ and ligand (5) and shows large dense masses with very small dense particles dispersed on the surface. Using energy dispersive $\mathrm{x}$-ray spectroscopy the large masses were identified as $\mathrm{KBr}$, and the small particles were composed of iron. The $\mathrm{KBr}$ is formed as a result of decoordination of $\mathrm{Br}$ from $\mathrm{FeBr}_{2}$ in the presence of $\mathrm{KOtBu}$. The particles reacted with the electron beam and therefore high magnification imaging was not possible. This indicates that the particles were likely bound to volatile solvent molecules such as THF 
which were liberated upon exposure to the electron beam. Coordination of THF to FeNPs has been previously reported and supported by extended X-ray absorption fine structure (EXAFS) experiments. ${ }^{48}$ This would suggest that the FeNPs generated in situ are stabilized by PNNP ligand and THF as a labile ligand, which also supports why the in situ generated catalyst has comparable activity to (1) in THF but is more rapidly deactivated in iPrOH. A similar analysis was conducted on catalytic solutions using (1). TEM showed dense clusters also identified as potassium salts and dense areas depicted in Figure 9 [right] identified as $\sim 4 \mathrm{~nm}$ FeNPs. Also scattered across the grid were larger $(8-12 \mathrm{~nm})$, poorly defined structures of widely varying sizes that were much less dense than the potassium and iron sections of the grid. Using a GIF-2000 energy filter these areas were analysed for select elements ${ }^{49}$ and were determined to be primarily composed of boron. This suggests that the PB identified by ${ }^{11} B$ NMR is coating the grids, and can be roughly characterized by TEM. Applying a similar energy filter and focusing on phosphorus, it could be shown that phosphorus was primarily bound to the NPs, as would be expected for the ligand. Size distribution analysis using ImageJ software of the FeNPs in Figure 9 [right] indicate that the NPs are $4.1 \pm 0.7 \mathrm{~nm}$ in diameter, and they appear to be fairly round in shape and moderately well dispersed. This fits within the size range observed for catalysis with (2) and (4) for $\mathrm{TH}^{34}$ and also matches closely with the AB dehydrogenation FeNPs reported by Xu et. al. ${ }^{30}$

Figure 9: TEM images of entry 29 [left] and entry 28 [right]

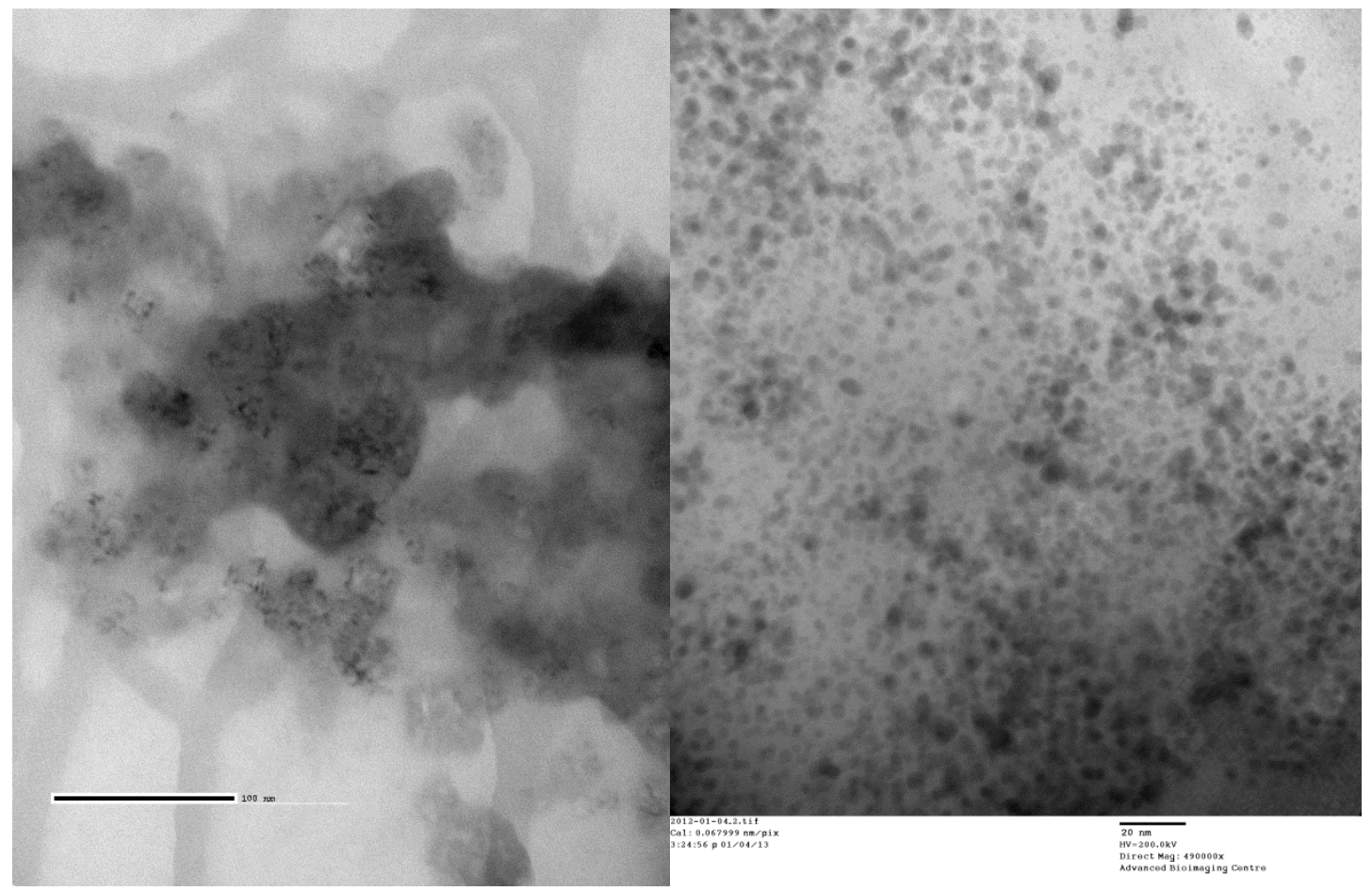

To complete our analysis of these new systems, we were interested in comparing them to our previously explored TH systems. ${ }^{34}$ To do this, we generated active catalyst for $A B$ dehydrogenation using our iron precatalysts with $A B$ and $\mathrm{KOtBu}$ in THF and then injected these activated solutions into isopropanol solutions containing acetophenone and monitored the conversion to 1-phenylethanol using gas chromatography (GC). Using the GC it is possible to monitor both overall conversion as well as product enantiopurity, so to get the most information out of our catalysis we chose to analyse our two chiral precatalysts (3) and (4). We previously explained (vide supra) that catalyst deactivation likely occurs during $A B$ dehydrogenation due to the binding of reactive boron compounds to the surface of the NPs. To minimize this deactivation before the catalysts could be used for TH we used less $A B$ for the 
formation of the active species. A precatalyst to base to $A B$ ratio of 1:7:8 in THF was used to reduce the iron and generate the active species and this activated solution was injected directly into a vial containing $\mathrm{iPrOH}$ and acetophenone, yielding a Fe to ketone ratio of 1:300. Typical TH employing (4) and a catalyst to substrate loading of 1:600 yielded $64 \%$ ee and $50 \%$ conversion in 30 minutes. ${ }^{34}$ Using the systems described herein we achieved $79 \%$ ee albeit catalysis took 4 hours to reach $50 \%$ conversion using (4), and no conversion was observed using (3). The high enantiopurity indicates that similar to the standard TH case, the chiral ligand must be bound to the surface to induce this level of selectivity. ${ }^{50,51}$ The increase in enantiopurity can be attributed to a selectivity enhancement induced by the preference of the system towards preformed catalyst versus in situ generated catalyst, as was observed previously for $\mathrm{TH}^{34}$ We hypothesized that the increase in selectivity was due to the unencumbered, complete formation of the ligand-coated nanoparticles without the interference of substrate, allowing for a more optimized coating of the chiral ligand on the surface. The fact that (4) and not (3) gave active catalysts for $\mathrm{TH}$ would indicate that the $\mathrm{CO}$ ligand present in precatalyst (4) must remain bound to the active species, and that it is necessary for TH. We observed this previously as (4) was active for TH and (3) was only active for direct hydrogenation. ${ }^{31}$ The presence of $\mathrm{CO}$ on the active surface therefore plays a critical but not well understood role in catalysis as it slows down AB dehydrogenation, but is crucial for TH. Lastly, it is worth noting the significant decrease in rate on going to the catalysts prepared in THF using $\mathrm{KOtBu}$ and $\mathrm{AB}$ versus the systems prepared with $\mathrm{KOtBu}$ in $\mathrm{iPrOH}$. This rate reduction can likely be attributed to a decrease in catalytic sites caused by the binding of reactive boron containing species to the surface, thereby acting as a catalyst poison. These studies further support that the active species during $A B$ dehydrogenation are FeNPs, similar to those previously investigated.

\section{Conclusions}

We have demonstrated the wide versatility of the series of iron complexes generally described as $\left[\mathrm{Fe}(\mathrm{NCMe})(\mathrm{L})\left(\mathrm{PPh}_{2} \mathrm{C}_{6} \mathrm{H}_{4} \mathrm{CH}=\mathrm{NCHR}-\right)_{2}\right]\left[\mathrm{BF}_{4}\right]_{2}$ for their use in the dehydrogenation of amine-boranes, particularly for ammonia-borane, on top of their efficient previous use as hydrogenation ${ }^{31,32,34}$ and oxidation ${ }^{35}$ catalysts. In isopropanol, 2.9 equivalents of $\mathrm{H}_{2}$ could be released in under an hour, yielding $\mathrm{B}(\mathrm{OiPr})_{3}$, whereas in non-protic solvents such as THF and diglyme B-N polymers and oligomers could be formed, and very rapid initial rates were observed yielding turn-over frequencies of up to 3.66 $\mathrm{H}_{2} /$ second. Catalysts were shown to be efficient at low temperatures, a quality not previously thoroughly investigated, and were shown to be completely poisoned by carbon monoxide. Electron microscopy imaging showed that iron nanoparticles were forming during catalysis, but could not confirm whether the true catalyst was heterogeneous, or if FeNPs are simply a deactivation product. To probe this property we tested hydrogen evolution using commercially available $\mathrm{Fe}^{2+}$ precursors in the presence of varying amounts of PNNP ligand. For a homogeneous catalyst we would expect to need a full equivalent of ligand to achieve comparable activity, however, we have shown that 1.2, 0.6, 0.3 and 0.15 equivalents of ligand all achieve the same activity, supporting that the active species are likely to be zero-valent iron nanoparticles coated in, and stabilized by, PNNP ligand, similar to what we observed previously for $\mathrm{TH}$ and oxidation with (2) and (4). ${ }^{34,35}$ Although these iron systems still hold many secrets, they have proven themselves to be quite versatile catalysts for a wide range of hydrogen reactions. Given the very rapid initial rates of catalysis it has proven to be quite difficult to run in operando studies to determine the true nature of the catalyst, ${ }^{52}$ and we can therefore only propose that the active species are zero-valent iron nanoparticles. 


\section{Acknowledgement}

We would like to thank Dr. Doug Holmyard and Dr. Neil Coombs for their invaluable help and expertise with TEM experiments. We would also like to thank the Natural Sciences and Engineering Research Council (NSERC) for a Discovery grant to R.H.M. and for a Canadian Graduate Scholarship and a Vanier Scholarship for J.F.S.

Supporting Information Available: File contains full experimental details, all catalytic profiles, relevant NMR spectra, electron microscopy images and experiments, kinetic profiles and TH results. This material is available free of charge via the internet at http://pubs.acs.org.

\section{References}

(1) Dunn, S. Int. J. Hydrogen Energy 2002, 27, 235.

(2) Schlapbach, L.; Zuttel, A. Nature 2001, 414, 353.

(3) Cook, T. R.; Dogutan, D. K.; Reece, S. Y.; Surendranath, Y.; Teets, T. S.; Nocera, D. G.

Chem. Rev. 2010, 110, 6474.

(4) Staubitz, A.; Robertson, A. P. M.; Manners, I. Chem. Rev. 2010, 110, 4079.

(5) Yadav, M.; Xu, Q. Energy Environ. Sci. 2012, 5, 9698.

(6) Staubitz, A.; Sloan, M. E.; Robertson, A. P. M.; Friedrich, A.; Schneider, S.; Gates, P. J.; Günne, J. r. S.; Manners, I. J. Am. Chem. Soc. 2010, 132, 13332.

(7) Baker, R. T.; Gordon, J. C.; Hamilton, C. W.; Henson, N. J.; Lin, P.-H.; Maguire, S.;

Murugesu, M.; Scott, B. L.; Smythe, N. C. J. Am. Chem. Soc 2012, 134, 5598.

(8) Sutton, A. D.; Burrell, A. K.; Dixon, D. A.; Garner, E. B.; Gordon, J. C.; Nakagawa, T.; Ott, K. C.; Robinson, J. P.; Vasiliu, M. Science 2011, 331, 1426.

(9) Lu, Z.; Conley, B. L.; Williams, T. J. Organometallics 2012, 31, 6705.

(10) Conley, B. L.; Guess, D.; Williams, T. J. J. Am. Chem. Soc 2011, 133, 14212.

(11) Blaquiere, N.; Diallo-Garcia, S.; Gorelsky, S. I.; Black, D. A.; Fagnou, K. J. Am. Chem. Soc 2008, 130, 14034.

(12) Denney, M. C.; Pons, V.; Hebden, T. J.; Heinekey, D. M.; Goldberg, K. I. J. Am. Chem. Soc. 2006, 128, 12048.

(13) Kim, S.-K.; Han, W.-S.; Kim, T.-J.; Kim, T.-Y.; Nam, S. W.; Mitoraj, M.; Piekoś, Ł.; Michalak, A.; Hwang, S.-J.; Kang, S. O. J. Am. Chem. Soc. 2010, 132, 9954.

(14) Conley, B. L.; Williams, T. J. Chem. Commun. 2010, 46, 4815.

(15) Käß, M.; Friedrich, A.; Drees, M.; Schneider, S. Angew. Chem. Int. Ed. 2009, 48, 905.

(16) Sewell, L. J.; Lloyd-Jones, G. C.; Weller, A. S. J. Am. Chem. Soc. 2012, 134, 3598.

(17) Schreiber, D. F.; O'Connor, C.; Grave, C.; Ortin, Y.; Müller-Bunz, H.; Phillips, A. D. ACS Catal. 2012, 2, 2505.

(18) Jiang, Y.; Blacque, O.; Fox, T.; Frech, C. M.; Berke, H. Organometallics 2009, 28, 5493.

(19) Clark, T. J.; Russell, C. A.; Manners, I. J. Am. Chem. Soc. 2006, 128, 9582.

(20) Keaton, R. J.; Blacquiere, J. M.; Baker, R. T. J. Am. Chem. Soc 2007, 129, 1844.

(21) Vogt, M.; de Bruin, B.; Berke, H.; Trincado, M.; Grutzmacher, H. Chem. Sci. 2011, 2, 723.

(22) Vance, J. R.; Robertson, A. P. M.; Lee, K.; Manners, I. Chem. Eur. J. 2011, 17, 4099.

(23) Kawano, Y.; Uruichi, M.; Shimoi, M.; Taki, S.; Kawaguchi, T.; Kakizawa, T.; Ogino, H. J. Am. Chem. Soc. 2009, 131, 14946.

(24) Jaska, C. A.; Temple, K.; Lough, A. J.; Manners, I. J. Am. Chem. Soc. 2003, 125, 9424.

(25) Kim, S.-K.; Kim, T.-J.; Kim, T.-Y.; Lee, G.; Park, J. T.; Nam, S. W.; Kang, S. O. Chem.

Commun. 2012, 48, 2021. 
(26) Zahmakran, M.; Philippot, K.; Ozkar, S.; Chaudret, B. Dalton Trans. 2012, 41, 590.

(27) Zahmakiran, M.; Özkar, S. Inorg. Chem. 2009, 48, 8955.

(28) Caliskan, S.; Zahmakiran, M.; Durap, F.; Ozkar, S. Dalton Trans. 2012, 41, 4976.

(29) Robertson, A. P. M.; Suter, R.; Chabanne, L.; Whittell, G. R.; Manners, I. Inorg. Chem. 2011, 50, 12680.

(30) Yan, J.-M.; Zhang, X.-B.; Han, S.; Shioyama, H.; Xu, Q. Angew. Chem. Int. Ed. 2008, 47, 2287.

(31) Sui-Seng, C.; Freutel, F.; Lough, A. J.; Morris, R. H. Angew. Chem. Int. Ed. 2008, 47, 940.

(32) Meyer, N.; Lough, A. J.; Morris, R. H. Chem. Eur. J. 2009, 15, 5605.

(33) Prokopchuk, D. E.; Sonnenberg, J. F.; Meyer, N.; Zimmer-De luliis, M.; Lough, A. J.; Morris, R. H. Organometallics 2012, 31, 3056.

(34) Sonnenberg, J. F.; Coombs, N.; Dube, P. A.; Morris, R. H. J. Am. Chem. Soc. 2012, 134, 5893.

(35) Sonnenberg, J. F.; Pichugin, D.; Coombs, N.; Morris, R. H. Top. Catal. 2013.

(36) Sui-Seng, C.; Haque, F. N.; Hadzovic, A.; Pütz, A. M.; Reuss, V.; Meyer, N.; Lough, A. J.; Zimmer-De luliis, M.; Morris, R. H. Inorg. Chem. 2009, 48, 735.

(37) Gao, J. X.; Zhang, H.; Yi, X. D.; Xu, P. P.; Tang, C. L.; Wan, H. L.; Tsai, K. R.; Ikariya, T. Chirality 2000, 12, 383.

(38) Mikhailine, A.; Lough, A. J.; Morris, R. H. J. Am. Chem. Soc. 2009, 131, 1394.

(39) Widegren, J. A.; Finke, R. G. J. Mol. Catal. A: Chem. 2003, 198, 317.

(40) Crabtree, R. H. Chem. Rev. 2012, 112, 1536.

(41) Lagaditis, P. O.; Lough, A. J.; Morris, R. H. Inorg. Chem. 2010, 49, 10057.

(42) Mikhailine, A. A.; Maishan, M. I.; Lough, A. J.; Morris, R. H. J. Am. Chem. Soc. 2012, 134, 12266.

(43) Prokopchuk, D. E.; Morris, R. H. Organometallics 2012, 31, 7375.

(44) Watzky, M. A.; Finke, R. G. J. Am. Chem. Soc. 1997, 119, 10382.

(45) Jaska, C. A.; Temple, K.; Lough, A. J.; Manners, I. Chem. Commun. 2001, 962.

(46) Pelter, A.; Levitt, T. E. Tetrahedron 1970, 26, 1545.

(47) Onak, T.; Landesman, H.; Williams, R.; Shapiro, I. J. Phys. Chem. 1959, 63, 1533.

(48) Welther, A.; Bauer, M.; Mayer, M.; Jacobi von Wangelin, A. ChemCatChem 2012, 4, 1088.

(49) Ahn, C. C.; Krivanek, O. L. EELS Atlas; ASU HREM and Gatan Inc.: United States, 1983.

(50) Bönnemann, H.; Braun, G. A. Angew. Chem. Int. Ed. 1996, 35, 1992.

(51) Osawa, T. Chem. Lett. 1985, 1609.

(52) Bayram, E.; Linehan, J. C.; Fulton, J. L.; Roberts, J. A. S.; Szymczak, N. K.; Smurthwaite, T. D.; Özkar, S.; Balasubramanian, M.; Finke, R. G. J. Am. Chem. Soc 2011, 133, 18889. 
TOC Graphic

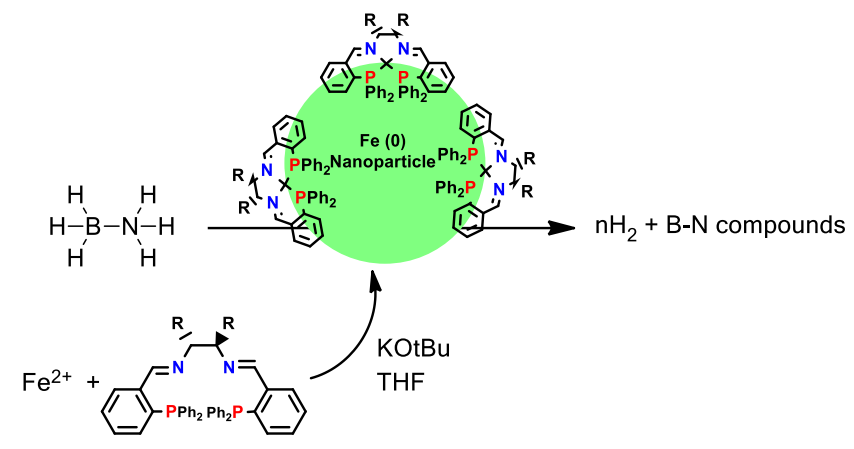

